\title{
Carbenoxolone decreases monocrotaline-induced pulmonary inflammation and pulmonary arteriolar remodeling in rats by decreasing the expression of connexins in $T$ lymphocytes
}

\author{
LIANG ZHANG $^{1,2^{*}}$, ZHI-RU FAN ${ }^{1,3^{*}}$, LU WANG $^{1,2^{*}}$, LU-QIAN LIU $^{1,2}$, \\ XIN-ZHI LI ${ }^{1,4}$, LI LI ${ }^{1,2}$, JUN-QIANG SI ${ }^{1,2}$ and KE-TAO MA ${ }^{1,2}$ \\ ${ }^{1}$ Department of Physiology, ${ }^{2}$ Key Laboratory of Xingjiang Endemic and Ethnic Diseases, \\ Medical College of Shihezi University, Shihezi, Xinjiang 832002; ${ }^{3}$ Department of Physiology, \\ Sanquan College of Xinxiang Medical University, Xinxiang, Henan 453003; ${ }^{4}$ Department of Pathophysiology, \\ Medical College of Shihezi University, Shihezi, Xinjiang 832002, P.R. China
}

Received July 16, 2019; Accepted October 11, 2019

DOI: $10.3892 / \mathrm{ijmm} .2019 .4406$

\begin{abstract}
The adaptive immune response mediated by $\mathrm{T}$ lymphocytes is a well-established factor in the pathogenesis of pulmonary inflammation. Changes in the expression of various connexins (Cxs) or disruption of connexin-mediated cellular communication in $\mathrm{T}$ lymphocytes contribute to inflammation or tissue remodeling. The aim of the present study was to investigate the potential therapeutic value of blocking Cxs in a monocrotaline (MCT)-induced pulmonary inflammation rat model. Carbenoxolone (CBX) was used to inhibit connexin-mediated cellular communication. An MCT rat model was established by intraperitoneal (i.p.) injection of a single dose of MCT $(60 \mathrm{mg} / \mathrm{kg})$, and CBX treatment $(20 \mu \mathrm{g} / \mathrm{kg} / \mathrm{day}$, i.p.) was initiated on the day following MCT treatment for 28 days. Vehicle-treated male Sprague-Dawley rats were used as the negative control. The MCT rat model was evaluated by measuring the pulmonary artery flow acceleration time and right ventricular hypertrophy index (RVHI). Histopathological features of the lung tissues and pulmonary arteriolar remodeling were assessed. The proportions of T lymphocyte subtypes, Cx40/cx43 expression in the $\mathrm{T}$ cell subtypes and the cytokine levels in the plasma and the lung tissues were also analyzed. Pharmacological inhibition of Cxs using CBX attenuated MCT-induced right ventricular hypertrophy, pulmonary arteriolar remodeling, lung fibrosis
\end{abstract}

Correspondence to: Professor Ke-Tao Ma or Professor Jun-Qiang Si, Department of Physiology, Medical College of Shihezi University, 59 North 2nd Road, Shihezi, Xinjiang 832002, P.R. China

E-mail: maketao@hotmail.com

E-mail: sijunqiang@shzu.edu.cn

\section{*Contributed equally}

Key words: carbenoxolone, monocrotaline, pulmonary inflammation, $\mathrm{T}$ lymphocytes, connexins and inflammatory cell infiltration by decreasing the RVHI, pulmonary arterial wall thickening, collagen deposition and pro-inflammatory cytokines production as well as $\mathrm{CD}^{+}$and $\mathrm{CD} 4^{+} \mathrm{T}$ cell accumulation in lung tissues of MCT-treated rats. Furthermore, flow cytometry analysis revealed that CBX may inhibit MCT-induced $\mathrm{Cx} 40$ and $\mathrm{Cx} 43$ expression in CD4 $4^{+}$ and $\mathrm{CD} 8^{+} \mathrm{T}$ lymphocytes in lung tissues. The present study provides evidence that pharmacological inhibition of Cxs may attenuate MCT-induced pulmonary arteriolar remodeling and pulmonary inflammatory response, at least in part, by decreasing $\mathrm{Cx}$ expression. The results highlight the critical role of Cxs in T lymphocytes in the MCT-induced pulmonary inflammatory response and that targeting of Cxs may be a potential therapeutic method for treating pulmonary inflammatory diseases.

\section{Introduction}

Pulmonary hypertension ( $\mathrm{PH})$ is a progressive and lethal pulmonary inflammatory disease characterized by sustained increases in pulmonary arterial pressure (PAP) and pulmonary arteriolar remodeling, which ultimately results in right heart hypertrophy, failure or even premature mortality (1-4). Development of PH is considered to involve the interaction between multiple factors (5). There is considerable circumstantial evidence that inflammatory responses serve a key role in the pathogenesis or progression of $\mathrm{PH}(6,7)$. Systemic or perivascular inflammation or immune dysregulation is a primary feature observed in patients with $\mathrm{PH}$ and experimental animal models of PH $(7,8)$. Pulmonary inflammation initiates and participates in the injury of pulmonary arterial endothelial cells and aberrant proliferation of pulmonary vascular smooth muscle cells, and subsequently accelerates the vascular remodeling and progression of $\mathrm{PH}(4,9)$. This remodeling is supported by histopathological data demonstrating infiltration of macrophages, monocytes and lymphocytes in the vicinity of the remodeled pulmonary arterioles and plexiform lesions of patients and animal models [hypoxia and the monocrotaline (MCT) rat model] of PH (10-12). In addition, increased 
levels of both serum and tissue pro-inflammatory cytokines have been observed in patients with $\mathrm{PH}$ and animal models of PH $(7,12)$. Despite an evident association between PH and dysregulation of the adaptive immune response, the regulatory mechanisms that result from alterations in lymphocyte subsets and the production of inflammatory cytokines from injured lung tissues and immune cells remain incompletely understood. Although immunosuppressive drugs and several immunotherapeutic approaches may alleviate inflammation and prevent vascular remodeling in animal models of PH (13-15), they lack therapeutic specificity (13-15). Therefore, further elucidating the molecular and cellular mechanism underlying $\mathrm{PH}-$ mediated inflammation and examining new immunotherapeutic strategies or agents is critical (14).

In our previous studies, it was demonstrated that connexin $(\mathrm{Cx})$-mediated gap junction channels in $\mathrm{T}$ lymphocytes of hypertensive animals and patients were involved in hypertension-mediated inflammation (16-18), and that expressional or functional inhibition of $\mathrm{Cx}(16-18)$, or treatment with various anti-inflammatory drugs $(\beta$-estradiol and hydrogen sulfide) $(19,20)$ improved hypertension- and pro-inflammatory stimuli-mediated inflammation by decreasing the proportion of $\mathrm{CD}^{+} \mathrm{T}$ lymphocytes and levels of pro-inflammatory cytokines (16-20). However, whether Cxs participate in $\mathrm{PH}$-mediated inflammation, and whether the inhibition of Cxs alleviates inflammation in $\mathrm{PH}$ remain unknown. Carbenoxolone (CBX), a semisynthetic derivative of glycyrrhetinic acid that inhibits gap junction activity (21), has been used to evaluate the role of Cx-mediated intercellular communication in acute lung inflammation (22), and to treat pulmonary inflammatory diseases $(23,24)$. Inhalation of CBX has been demonstrated to significantly decrease lung inflammation in experimental asthma animal models, by decreasing the production of interleukin (IL) -4 and -5 and by decreasing the infiltration of inflammatory cells in perivascular regions (24). In addition, CBX has been demonstrated to decrease differentiation of Th17 cells by decreasing IL-23 production in antigen presenting cells (25). Based on our and other published studies, it was hypothesized that CBX may alleviate PH-mediated inflammation by regulating Cxs or gap junctions in T lymphocytes.

Studies have demonstrated that the MCT-treated rat model and $\mathrm{PH}$ exhibit similar pathological characteristics in vascular remodeling, production of inflammatory cytokines and infiltration of inflammatory cells $(2,8)$; therefore, this model was deemed to be well-suited for studying the anti-inflammatory effects and corresponding molecular mechanisms of CBX on MCT-induced pulmonary inflammation, and to examine the association between Cxs function in T cells and MCT-induced pulmonary inflammation. To investigate the therapeutic effects of CBX on inflammation and pulmonary arteriolar remodeling caused by MCT, physiological and echocardiographic parameters in the heart were measured, histopathological changes in lung tissues were assessed, and the levels of cytokines and distribution of $\mathrm{CD}^{+}$and $\mathrm{CD}^{+} \mathrm{T}$ cells in lung tissues were determined in CBX-treated MCT rats. Additionally, to the best of our knowledge, the present study was the first to determine whether $\mathrm{Cx} 40$ and $\mathrm{Cx} 43$ may serve as potential therapeutic targets in $\mathrm{PH}$-mediated inflammation, and whether CBX may improve the pro-inflammatory microenvironment in a rat MCT model by regulating $\mathrm{Cx} 40$ and $\mathrm{Cx} 43$ expression in $\mathrm{T}$ cell subsets. Although the precise molecular mechanisms of CBX-mediated regulation of Cxs are incompletely understood, the role of Cxs in T cells in the progression of MCT-mediated pulmonary inflammation was investigated, and the inhibition of Cxs or Cxs-based gap junctions using CBX may be a potential therapeutic method for attenuating inflammatory lung injury.

\section{Materials and methods}

Establishment of the animal model and treatment schedules. Male Sprague-Dawley rats (age, 8-10 weeks; body weight, 200-250 g) were obtained from Beijing Vital River Laboratory Animal Technology Co., Ltd. All rats were housed in a specific pathogen-free barrier facility with a 12: $12 \mathrm{~h}$ day: night cycle at $22 \pm 2^{\circ} \mathrm{C}$ and $60-65 \%$ humidity. Rats had ad libitum access to chow and water. All animal experimental protocols were approved by the Institutional Animal Care and Use Committee of the Medical College of Shihezi University (permit no. A2019-027-01) and all experiments were performed in strict accordance with the Guidelines on the Care and Use of Animals provided by the American Physiological Society (NIH Publication no. 85-23, revised 1996) (26).

A total of 24 rats were used, and were randomly divided into the following four groups, with 6 rats/group: Control group; CBX-treated rats (cat. no. C4790; Sigma-Aldrich; Merck $\mathrm{KGaA}$ ); MCT group; and MCT rats treated with CBX (MCT + CBX group). Rats from the MCT and MCT + CBX groups received a single intraperitoneal (i.p.) injection of MCT (cat. no. C2401; 60 mg/kg; day 0; Sigma-Aldrich; Merck $\mathrm{KGaA})$. The rats in the MCT $+\mathrm{CBX}$ group received daily i.p. injections of CBX $(20 \mathrm{mg} / \mathrm{kg})$ for 28 days following MCT administration, whereas the control rats received daily i.p. administration of normal saline or CBX from day 0 to day 28. The CBX dose used was based on a previous study (27). On day 28, all animals underwent echocardiography measurement. Rats were then sacrificed under deep anesthesia by i.p. administration of sodium pentobarbital $(100 \mathrm{mg} / \mathrm{kg})$, and the lungs, hearts and blood samples were collected.

Doppler echocardiography measurement. The Doppler echo parameter 'pulmonary artery acceleration time' (PAAT) is negatively correlated with the mean pulmonary arterial pressure (PAP) measured invasively, namely increased pulmonary hypertension or an increase in PAP as judged by a decreased PAAT $(28,29)$. Therefore, PAAT is considered as an echocardiographic indicator of PH (30). PH was also assessed using Doppler echocardiography at day 28 of the study. Transthoracic closed-chest echocardiography was performed by an experienced doctor using a Vivid E9 ultrasound system equipped with a 12-MHz transducer (GE Healthcare). Rats were anesthetized by i.p. injection of $3 \%$ sodium pentobarbital $(40 \mathrm{mg} / \mathrm{kg})$ and placed in a shallow left lateral decubitus position, and an ultrasound gel was applied to the shaved chest. Blood flow through the pulmonary artery and PAAT were measured in the two-dimensional short-axis parasternal view by M-mode and Pulsed-wave Doppler at the level of the pulmonary valve. Papillary muscles were used as the reference point for echocardiography measurements. PAAT was measured from the onset of systolic flow to peak pulmonary outflow velocity according 
to the American Society of Echocardiography guidelines (31). The acquisition of Echo images and all the echocardiographic analyses were performed using Echopac BT11 software (v.6.5; GE Healthcare).

Measurement of right-ventricular hypertrophy. Rats were sacrificed under deep anesthesia by i.p. administration of sodium pentobarbital $(100 \mathrm{mg} / \mathrm{kg})$, and the entire heart was isolated, immediately dissected and weighed to assess right-ventricular hypertrophy (RVH). The atria and extraneous blood vessels were removed from the isolated heart in cooled $0.9 \%$ saline solution. Subsequently, the two ventricles of the heart were separated into the free right ventricle (RV) and the left ventricle (LV) wall with the interventricular septum (S), and the 2 portions were immediately blotted dry and weighed separately. Finally, a weight ratio of RV to LV plus $\mathrm{S}[\mathrm{RV} /(\mathrm{LV}+\mathrm{S})]$ was calculated for determination of the RVH index (RVHI).

Histopathological examination of lung tissues. The left lung tissues obtained from sacrificed rats were fixed in $4 \%$ paraformaldehyde for $48 \mathrm{~h}$ at $4^{\circ} \mathrm{C}$, embedded in paraffin and cut into $4 \mu \mathrm{m}$-thick sections using a microtome. Sections were stained with hematoxylin and eosin or Masson trichome staining according to the manufacturer's protocol (cat. no. 1345; Beijing Solarbio Science \& Technology Co., Ltd.), and the histopathological changes in lung tissues and pulmonary arterioles (small arterioles with an external diameter of 15-50 $\mu \mathrm{m}$ and medium-sized arterioles with an external diameter of 50-150 $\mu \mathrm{m}$ ) were examined under a light microscope and imaged using a digital camera (BX51; Olympus Corporation) at a magnification, $\mathrm{x} 200$ or $\mathrm{x} 400$. For quantitative analysis, the microscopic images of lung tissue sections were analyzed using Image-Pro Plus v.6.0 (Media Cybernetics, Inc.). Pulmonary vascular remodeling in the arterioles was evaluated by the percentage of vascular wall thickness (WT\%) and the percentage of the vascular wall area (WA\%). The formula for WT\% was: WT\% $=[2 \times$ (external diameter of the pulmonary arterioles - internal diameter of the pulmonary arterioles)]/(external diameter of the pulmonary arterioles) $\mathrm{x} 100$; and the formula for WA\% was: WA $\%=($ external area internal area)/external area $\mathrm{x} 100$. The formula for WT\% and WA\% was carried out as described by Yang et al (8) with some minor modifications. A total of 20 randomly selected pulmonary arterioles/rat (6 rats/group) that were nearly round were analyzed and the average from each group was calculated. Pulmonary vascular remodeling and lung fibrosis was assessed using Image-Pro Plus v.6.0 by 2 professional pathologists whom each assessed 20 different non-overlapping fields of each section. The lung fibrosis index was analyzed by calculating the ratio of the total area of collagen to the total area of connective tissue in each visual field (32).

ELISA. Blood samples $(5 \mathrm{ml})$ from the abdominal aorta of anesthetized rats were allowed to clot for $15 \mathrm{~min}$ at $22-25^{\circ} \mathrm{C}$, centrifuged at $1,100 \mathrm{x}$ g for $10 \mathrm{~min}$ at $4^{\circ} \mathrm{C}$ and the plasma was collected and stored at $-80^{\circ} \mathrm{C}$. The right lung tissues $(400 \mathrm{mg})$ obtained from rats were minced extensively and homogenized for $30 \mathrm{sec}$ using an ultrasonic homogenizer (Beijing HeDe Biotechnology Co., Ltd.) in PBS (pH 7.2; lung tissue to PBS,
1:10) on ice. Samples were then centrifuged at $12,000 \mathrm{x} g$ for 15 min at $4^{\circ} \mathrm{C}$, and the lung tissue supernatant was obtained. Both the lung tissue supernatant and previously prepared serum were used to measure the concentrations of IL- $1 \beta$ (cat. no. 70-EK301B), IL-6 (cat. no. 70-EK3062/2), IL-10 (cat. no. 70-EK3102/2) and tumor necrosis factor- $\alpha$ (TNF- $\alpha$; cat. no. 70-EK382HS-96) using ELISA kits (Hangzhou Multi-Sciences Biotech Co., Ltd.) according to the manufacturer's protocols. Measurements of each sample were performed 3 times and the inflammatory cytokine concentrations are expressed as $\mathrm{pg} / \mathrm{ml}$ of the supernatant.

Preparation of mononuclear cells from lung tissues. Washed right lung tissues were dissociated into single-cell suspensions as described previously, with certain modifications (33-35). Lung tissues were minced with sterilized scissors and forceps [RNase was inactivated by high temperature $\left(121^{\circ} \mathrm{C}\right)$ ], and were enzymatically digested with RPMI-1640 medium (cat. no. 11875085; Gibco; Thermo Fisher Scientific, Inc.) supplemented with $1 \%$ BSA (Beijing Solarbio Science \& Technology Co., Ltd.), $10 \mathrm{mmol} / 1$ HEPES, 60 units $/ \mathrm{ml}$ deoxyribonuclease I (cat. no. D4527), $1 \mathrm{mg} / \mathrm{ml}$ type XI collagenase (cat. no. C7657), 1,000 U hyaluronidase (cat. no. H3631), and 0.1 $\mathrm{mg} / \mathrm{ml}$ Kunitz-type soybean trypsin inhibitor (cat. no. 7659; Sigma-Aldrich; Merck KGaA), and the tissues were agitated for $40 \mathrm{~min}$ in a $37^{\circ} \mathrm{C}$ incubator. Following digestion, the lung tissue and supernatant were filtered through a 200 -gauge stainless steel mesh to remove cell clumps and undigested tissue. The filtered suspension was centrifuged at $200 \mathrm{xg}$ for $10 \mathrm{~min}$ at room temperature, and lung cells were resuspended in FACS buffer (cat. no. 00-4222-57; Thermo Fisher Scientific, Inc.) at a concentration of $\sim 2 \times 10^{6} / \mathrm{ml}$. The number of live cells was measured using light microscopy at low resolution (magnification, $\mathrm{x} 40$ ) by staining cells with $0.4 \%$ Trypan Blue for $10 \mathrm{~min}$ at $22-25^{\circ} \mathrm{C}$.

Flow cytometry. All isolated mononuclear cells $\left(>1 \times 10^{6}\right.$ cells $/ \mathrm{ml}$ ) harvested from lung tissues in $500 \mu \mathrm{L}$ FACS buffer were blocked via incubation with 5\% normal mouse serum (cat. no. 31880; Invitrogen; Thermo Fisher Scientific, Inc.) for $15 \mathrm{~min}$ at $4^{\circ} \mathrm{C}$. Cells were subsequently stained with fluorescein isothiocyanate (FITC)-conjugated anti-rat CD3 (cat. no. 201403), allophycocyanin (APC)-conjugated anti-rat CD4 (cat. no. 201509) and phycoerythrin (PE)-conjugated anti-rat CD8 (cat. no. 201705) antibodies (all at 1:100; all from BioLegend, Inc.) at $4^{\circ} \mathrm{C}$ for $30 \mathrm{~min}$. FITC-, APC-, and PE- labelled IgGlor IgM isotype were used as negative controls (1:100; cat. no. 401607 for FITC-conjugated isotype ctrl antibody; cat. no. 400111 for PE-conjugated mouse isotype ctrl antibody; cat. no. 400119 for APC-conjugated isotype ctrl antibody; Biolegend, Inc.). For the labeling of $\mathrm{Cxs}$ in $\mathrm{CD}^{+}$or $\mathrm{CD}^{+} \mathrm{T}$ cells from lung tissues, stained T cells with APC-labeled anti-CD4 and PE-labeled anti-CD8 antibodies were incubated with permeabilization solution (Cytofix/Cytoperm kit; BD Biosciences) for $30 \mathrm{~min}$ at room temperature. Following permeabilization, cells were incubated with anti-Cx40 monoclonal antibody (1:100; cat. no. sc-365107; Santa Cruz Biotechnology, Inc.) or anti-Cx43 antibody (1:100; cat. no. sc-13558; Santa Cruz Biotechnology, Inc.) for $30 \mathrm{~min}$ at $4^{\circ} \mathrm{C}$. Following washing using FACS buffer, the T cells were 

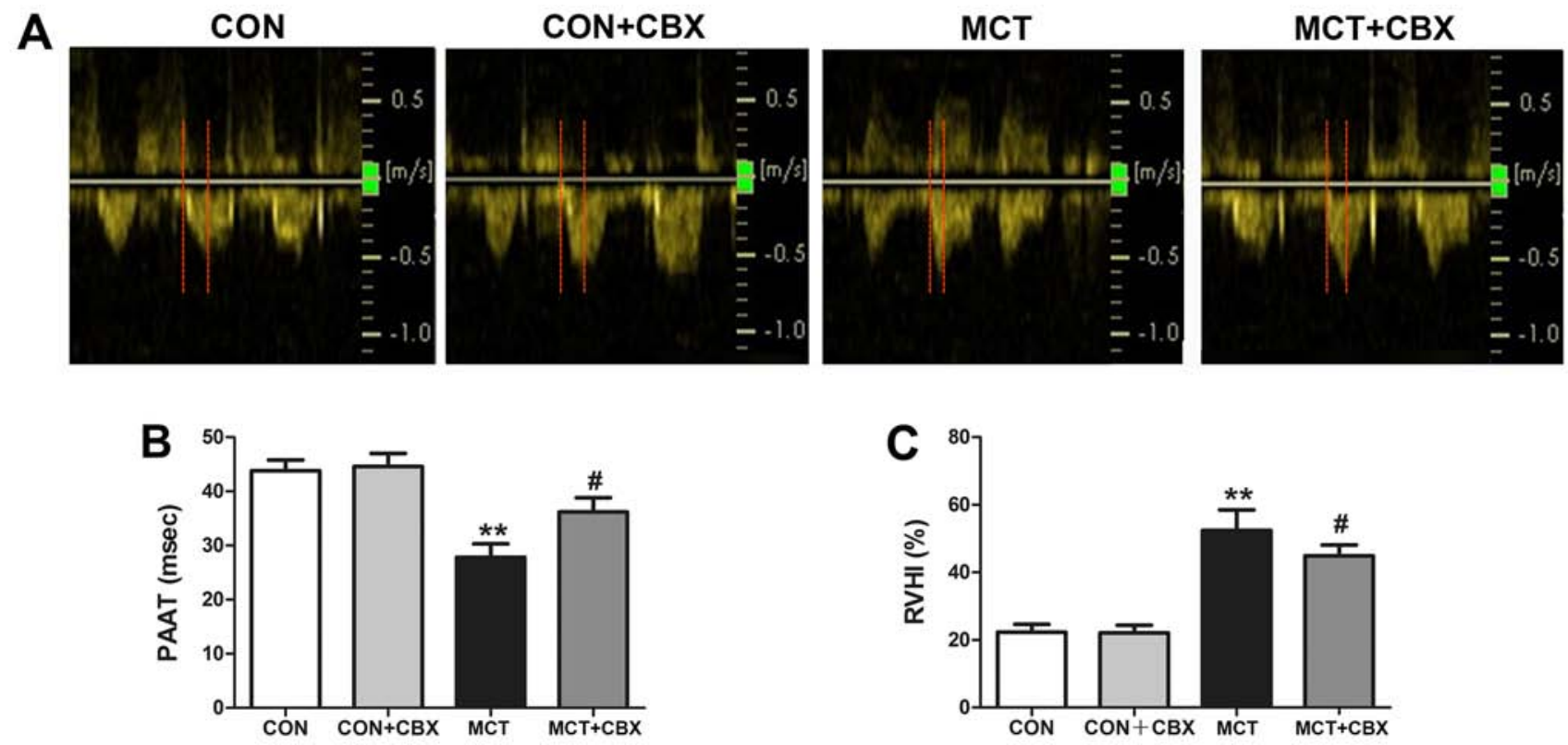

Figure 1. CBX attenuates MCT-induced pulmonary hypertension and right ventricular hypertrophy in an MCT-induced rat model of pulmonary inflammation. (A) Representative pulse-wave Doppler acquisition of pulmonary flow in the control, CBX + single intraperitoneal injection of CBX, MCT and MCT + CBX groups. The distance between the 2 red dashed line in each group represents PAAT. (B) PAAT from onset of pulmonary valve flow to peak velocity as a surrogate measure of mean pulmonary arterial pressure measured by pulsed wave-Doppler echocardiography. PAAT is negatively correlated to mean pulmonary arterial pressure and pulmonary vascular resistance measured. Statistical analysis of PAAT in the four experimental groups. PAAT was significantly decreased in the MCT treatment group compared with the control group after 28 days. Treatment with CBX significantly increased PAAT compared with the MCT group. (C) CBX administration decreased RVHI (the ratio of RV weight/left ventricular plus septal weight) in MCT-treated rats. Data are presented as the mean \pm standard error of the mean of 6 rats per group. ${ }^{* *} \mathrm{P}<0.01$ vs. Control and $\mathrm{CBX}$ group treated with a single intraperitoneal injection of $\mathrm{CBX}$. ${ }^{\#} \mathrm{P}<0.05$ vs. MCT + CBX group. CBX, carbenoxolone; MCT, monocrotaline; CON, control; PAAT, pulmonary artery valve flow acceleration time; RVHI, right ventricle hypertrophy index.

then incubated with a FITC-conjugated anti-mouse secondary antibody (1:100; cat. no. ZF0312; OriGene Technologies, Inc.) for $30 \mathrm{~min}$ at $4^{\circ} \mathrm{C}$ in the dark. All stained cells were analyzed using a FACSort flow cytometer (BD Pharmingen; BD Biosciences) together with BD CellQuest Pro software (v.2.0, system OS2; Becton Dickinson and Company). Double-color flow cytometry was performed to calculate the percentages of CD4/CD8 positive T cells, and $\mathrm{Cx} 40 / \mathrm{Cx} 43$ expression in different $\mathrm{T}$ lymphocyte subpopulations.

Statistical analysis. All experimental data are presented as the mean \pm standard error of mean of 3 independent experiments. GraphPad Prism v.5.0 (GraphPad Software, Inc.) was used for statistical analysis. Comparisons between two groups were performed using an unpaired Student's t-test, and comparisons between multiple groups were performed using a one-way analysis of variance followed by Tukey's post hoc test. $\mathrm{P}<0.05$ was considered to indicate a statistically significant difference.

\section{Results}

Administration of $C B X$ prevents MCT-induced hemodynamic changes. A change in the shape of the pulmonary artery outflow waveform in combination with PAAT have been demonstrated to be a good echocardiographic indicator of PH (36); therefore, doppler echocardiography was used to confirm the establishment of MCT-induced PH (Fig. 1A and B). Fig. 1A shows representative images of the pulmonary artery flow pattern among the four groups of rats. Compared with the Control and CBX group, the MCT rats exhibited a profile of pulmonary artery flow with more triangular, dagger-shaped signals, indicative of high resistance in the pulmonary artery (Fig. 1A). By contrast, $\mathrm{CBX}$ administration attenuated the high resistance induced by MCT (Fig. 1A). Doppler echocardiography of the MCT group indicated that PAAT was significantly decreased

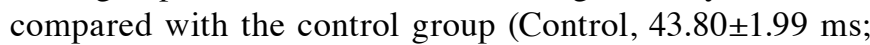
MCT, 27.80 $\pm 2.52 \mathrm{~ms}$; $\mathrm{P}<0.01$; Fig. 1B), indicating that the rats in the MCT group developed $\mathrm{PH}$. The effect of $\mathrm{CBX}$ on pulmonary artery function was investigated by measuring PAAT at the end of the treatment period. Intraperitoneal administration of CBX significantly increased PAAT compared with the MCT-treated rats $(\mathrm{MCT}=27.80 \pm 2.52 \mathrm{~ms}$; $\mathrm{MCT}+\mathrm{CBX}=36.20 \pm 2.60 \mathrm{~ms} ; \mathrm{P}<0.05 ;$ Fig. 1B). These results suggest that $\mathrm{CBX}$ administration prevented the effect of MCT-mediated induction of PH.

$\mathrm{RVH}$ is associated with $\mathrm{PH}$, therefore right ventricular hypertrophy was evaluated by measuring the RVHI. RVHI in the MCT group was significantly increased compared with the control group (Control=22.33 $\pm 0.94 \%$; $\mathrm{MCT}=52.46 \pm 2.48 \%$; $\mathrm{P}<0.01$; Fig. 1C), suggesting that rats exhibited RVH as a consequence of elevated pulmonary pressure when treated with MCT. CBX administration of MCT-treated rats ameliorated the deleterious effect of $\mathrm{PH}$-induced $\mathrm{RVH}$ in rats, as depicted by the decreased RVHI compared with the rats treated with MCT alone $(\mathrm{MCT}=52.46 \pm 2.48 \%$; $\mathrm{MCT}+\mathrm{CBX}=44.90 \pm 1.32 \%$; $\mathrm{P}<0.05$; Fig. 1C).

Administration of CBX attenuates MCT-induced pulmonary vascular remodeling, lung fibrosis and inflammatory cell infiltration. The effect of MCT on pulmonary vascular 
A

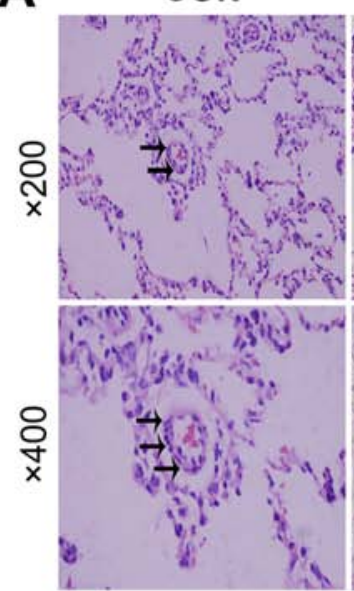

CON+CBX

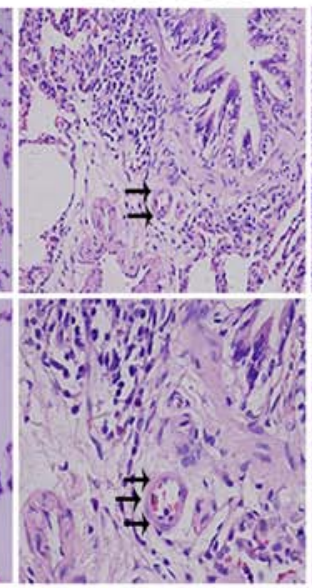

MCT

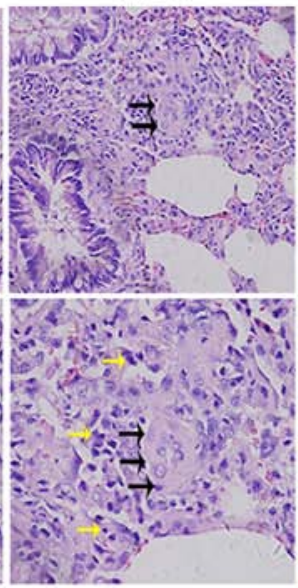

MCT+CBX

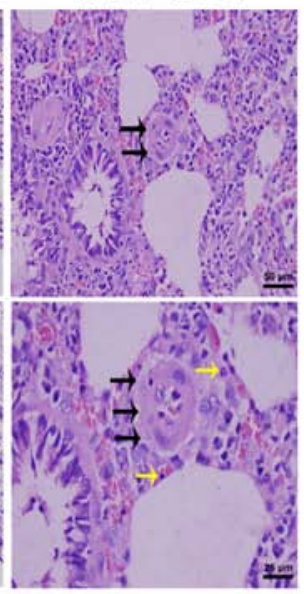

B
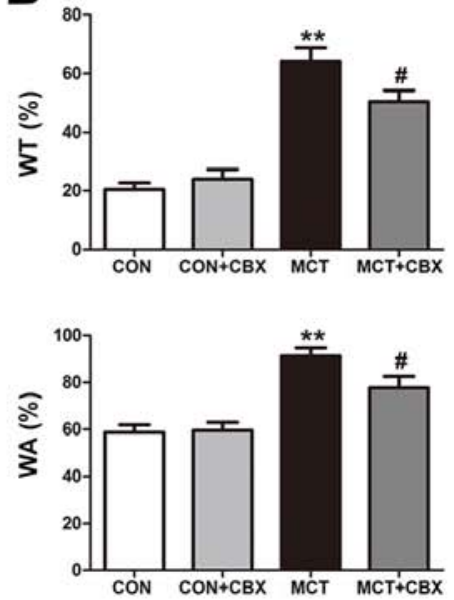

Figure 2. MCT-induced remodeling of small pulmonary arterioles and inflammatory cell infiltration is alleviated by CBX. (A) Representative hematoxylin and eosin staining demonstrating histopathological changes in small pulmonary arterioles at magnification, $\mathrm{x} 200$ (scale bar=50 $\mu \mathrm{m}$; upper panel) and magnification, $x 400$ (scale bar=25 $\mu \mathrm{m}$; lower panel). Pulmonary arteriole walls in the control group were thin and single layered. The intima, media and externa were difficult to distinguish. Pulmonary vascular remodeling was observed in MCT-treated animals, characterized by obliterated vessels (black arrows); no obliteration was detected in the control rats and the rats treated with a single intraperitoneal injection of CBX. CBX prevented pulmonary arterial obliteration in small pulmonary arterioles of MCT-treated animals. The black and yellow arrows indicate pulmonary arterial obliteration and perivascular infiltration of inflammatory cells in small pulmonary arterioles, respectively. (B) WT\% and WA\% of the MCT-treated rats were significantly increased, and CBX treatment of the MCT rats significantly decreased WT\% and WA\%. Data are presented as the mean \pm standard error of the mean of 6 rats/group. ${ }^{* *} \mathrm{P}<0.01$ vs. control. ${ }^{\#} \mathrm{P}<0.05$ vs. MCT group. CBX, carbenoxolone; MCT, monocrotaline; CON, control; WT\%, percentage of vascular wall thickness; WA $\%$, percentage of the vascular wall area.

A
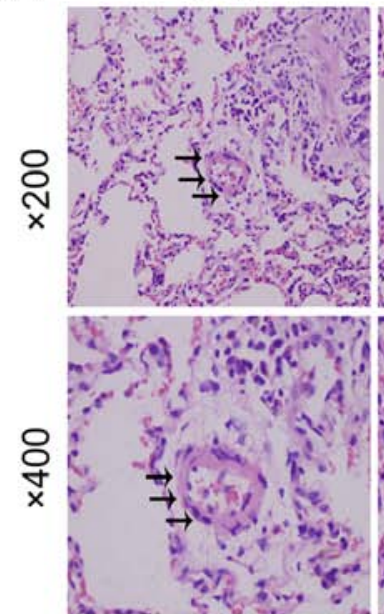

CON+CBX

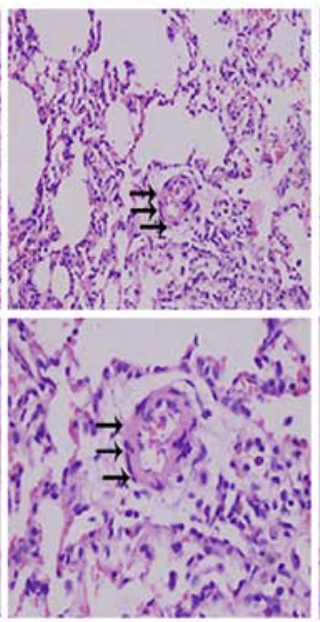

MCT
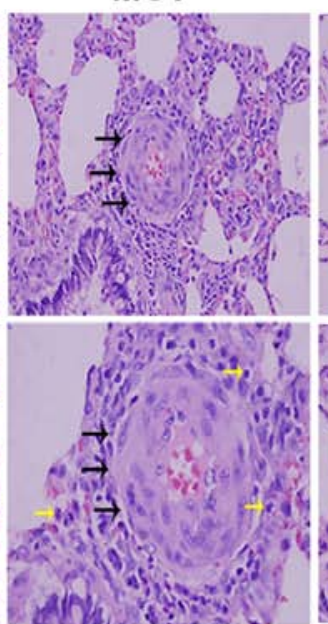

MCT+CBX

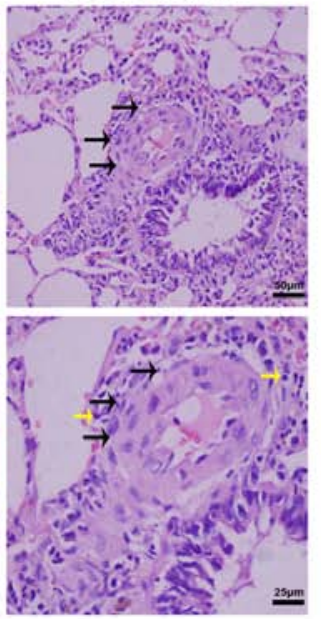

B
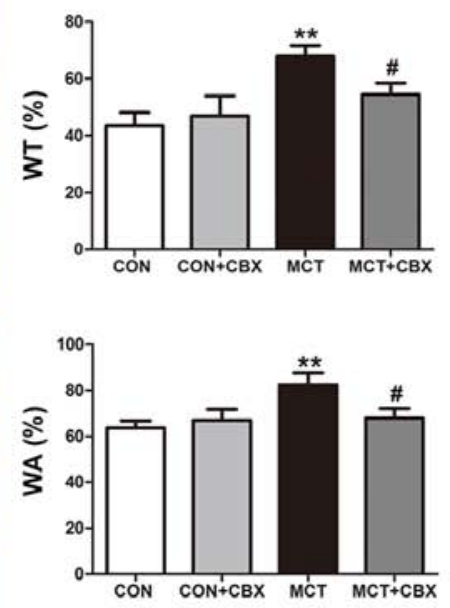

Figure 3. Administration of CBX prevents MCT-induced remodeling of medium-sized pulmonary arterioles. (A) Representative hematoxylin and eosin staining indicating the histopathological changes in medium-sized pulmonary arterioles at magnification, $\mathrm{x} 200$ (scale bar=50 $\mu \mathrm{m}$; upper panel) and magnification, $\mathrm{x} 400$ (scale bar=25 $\mu \mathrm{m}$; lower panel). MCT-treated animals had obliterated vessels (black arrows). No obliteration was observed in the control rats or rats treated with a single intraperitoneal injection of CBX. CBX administration did not decrease lumen obliteration of medium-sized pulmonary arterioles. Black and yellow arrows indicate pulmonary arterial obliteration and perivascular infiltration of inflammatory cells in medium-sized pulmonary arterioles, respectively. (B) WT\% and WA\% were significantly increased in MCT-treated rats, and CBX treatment of the MCT rats significantly decreased WT\% and WA\% in the medium-sized pulmonary arteries compared with those in MCT-treated animals. Data are presented as the mean \pm standard error of the mean of 6 rats/group. ${ }^{* *} \mathrm{P}<0.01$ vs. control. ${ }^{\#} \mathrm{P}<0.05$ vs. MCT group. CBX, carbenoxolone; MCT, monocrotaline; CON, control; WT\%, percentage of vascular wall thickness; WA $\%$, percentage of the vascular wall area.

remodeling in small arterioles and medium arterioles of lungs in the rat model were determined, and the effect of CBX administration on MCT-induced pulmonary arteriolar remodeling were evaluated (Fig. 2 and 3). Compared with the control rats, MCT treatment significantly induced muscularization, stenosis and occlusion of the arterioles in the lungs, and this was accompanied by inflam- matory cell infiltration around the vessel wall and lung tissues (Fig. 2A and 3A). The WT\% in the small (Control $=20.45 \pm 2.24$; $\mathrm{MCT}=64.21 \pm 4.47 \%)$ and medium pulmonary arterioles (Control $=43.51 \pm 4.62 ; \mathrm{MCT}=67.82 \pm 3.88 \%$ ), and the WA\% in the small (Control=58.74 \pm 3.15 ; MCT $=91.24 \pm 3.34 \%$ ) and medium pulmonary arterioles (Control $=63.71 \pm 3.07$; $\mathrm{MCT}=82.56 \pm 5.04 \%$ ) were significantly increased in the 


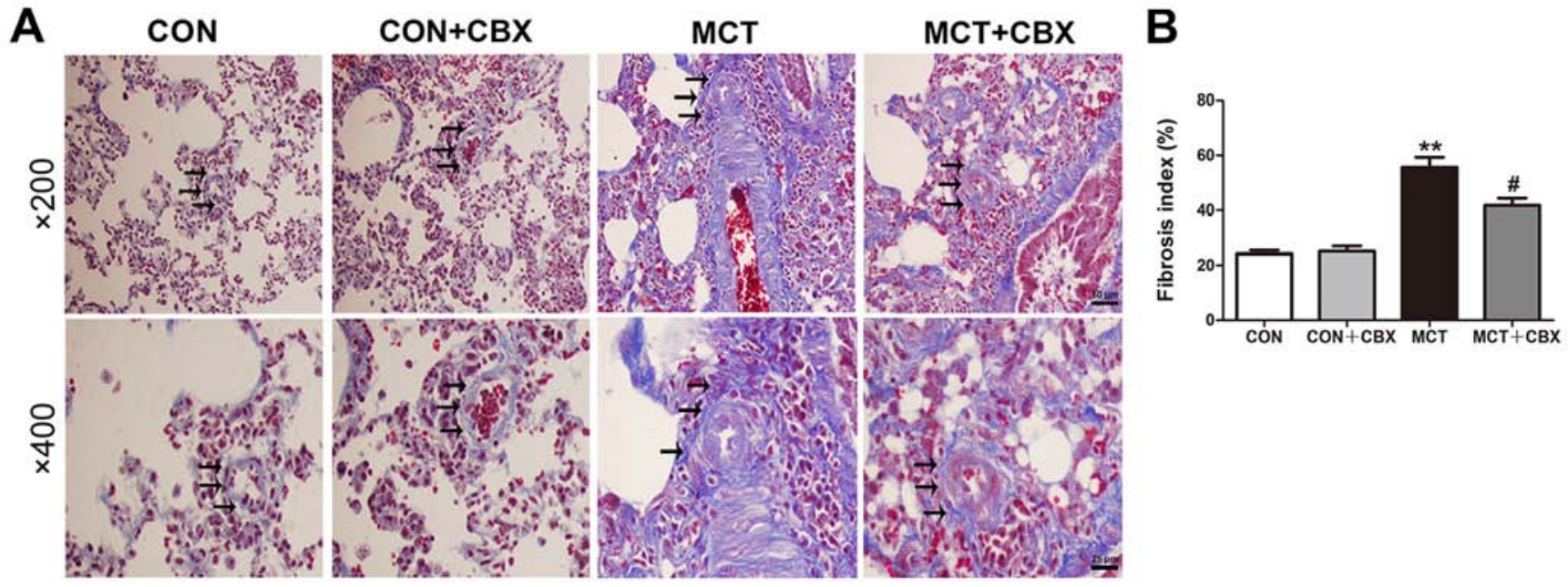

Figure 4. Administration of CBX ameliorates MCT-induced pulmonary fibrosis. (A) Masson trichrome staining of lung tissue at magnification, x200 (scale bar $=50 \mu \mathrm{m}$; upper panel) and magnification, $\mathrm{x} 400$ (scale bar $=25 \mu \mathrm{m}$; lower panel). Black arrows indicate collagen deposition, indicative of fibrosis, and collagen fibers are stained blue. Nuclei are stained dark red/purple, and the cytoplasm is stained red/pink. (B) Quantification of interstitial fibrosis as a percentage derived from positive collagen staining. The lung fibrosis index was defined as the percentage of the total area stained with collagen divided by the sum of total connective tissue area in the entire visual field. Data are presented as the mean \pm standard error of the mean of 6 rats/group. ${ }^{* *} \mathrm{P}<0.01$ vs. control. ${ }^{\#} \mathrm{P}<0.05$ vs. MCT group. CBX, carbenoxolone; MCT, monocrotaline; CON, control.
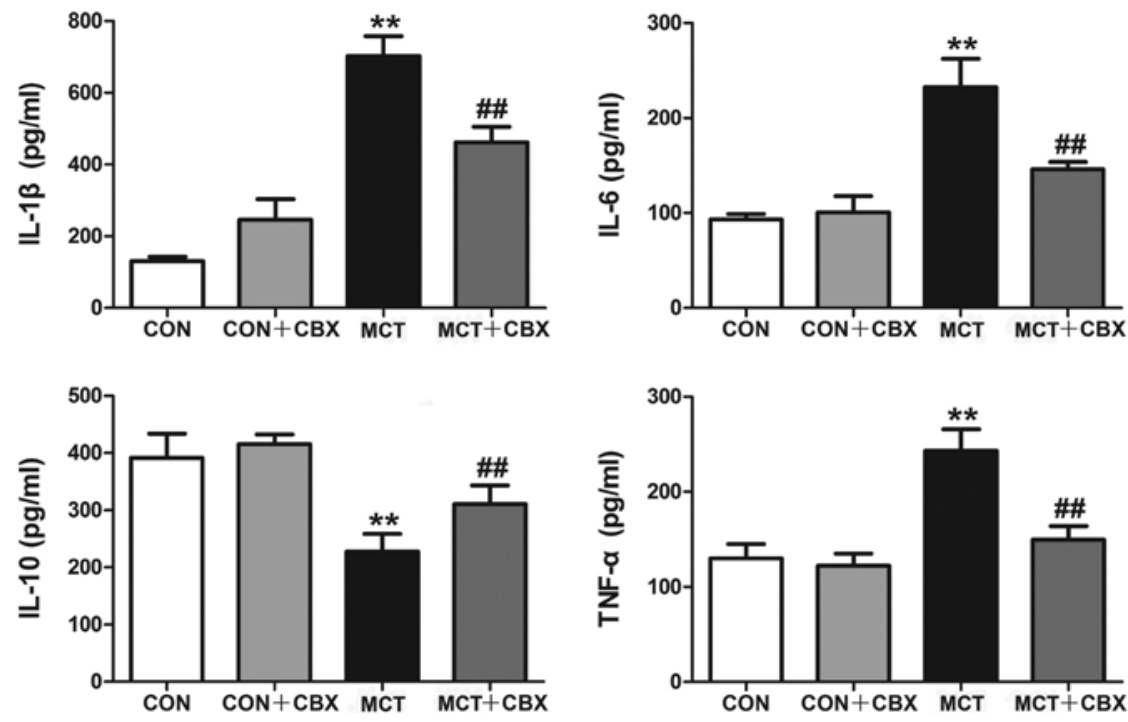

Figure 5. Effect of CBX on cytokine production in rat lung tissues treated with MCT. Images indicate the protein expression levels of IL-1 $\beta$, IL-6, IL-10 and TNF- $\alpha$ in rat lung tissues. Pulmonary levels of IL-1 $\beta$, IL- 6 and TNF- $\alpha$ were significantly elevated in MCT-treated animals compared with the control rats. Pulmonary levels of IL-10 were decreased in MCT treated rats compared with the control group. Pro-inflammatory cytokines IL-1 $\beta$, IL-6 and TNF- $\alpha$ were increased in MCT-induced inflammation, and CBX treatment significantly decreased the levels of these cytokines. IL-10 levels were increased in the lung tissues of the CBX-treated rats compared with the MCT-treated animals. Data are presented as the mean \pm standard error of the mean of 6 rats/group. ${ }^{* * *} \mathrm{P}<0.01$ vs. control. ${ }^{\# \#} \mathrm{P}<0.01$ vs. MCT treatment group. CBX, carbenoxolone; IL, interleukin; MCT, monocrotaline; CON, control; TNF- $\alpha$, tumor necrosis factor- $\alpha$.

MCT-treated rats compared with the control (all $\mathrm{P}<0.01$ Fig. 2B and 3B). CBX administration prevented medial hypertrophy, occlusion and muscularization of the pulmonary arterioles, as well as inflammatory infiltration compared with the MCT-treated rats (Fig. 2A and Fig. 3A). In particular, CBX significantly decreased the MCT-induced increase in WT\% in the small (MCT=64.21 $\pm 4.47 \%$; $\mathrm{MCT}+\mathrm{CBX}=50.41 \pm 3.80 \%)$ and in medium pulmonary arterioles $(\mathrm{MCT}=67.82 \pm 3.88 \%$; $\mathrm{MCT}+\mathrm{CBX}=54.53 \pm 3.98 \%)$, and the WA\% in the small $(\mathrm{MCT}=91.24 \pm 3.34 \% ; \mathrm{MCT}+\mathrm{CBX}=77.62 \pm 5.04 \%)$ and medium pulmonary arterioles $(\mathrm{MCT}=82.56 \pm 5.04 \%$; $\mathrm{MCT}+\mathrm{CBX}=67.93 \pm 4.20 \%)($ all $\mathrm{P}<0.05$; Fig. $2 \mathrm{~B}$ and Fig. $3 \mathrm{~B})$.
Lung fibrosis is a primary feature of MCT-induced pulmonary inflammation (37). Masson trichrome staining was used to demonstrate the presence of fibrosis by collagen deposition. The results of Masson staining indicated that the MCT-treated rats displayed notable collagen deposition in the interstitium and arteries of the lungs compared with the control rats (Control=24.18 $\pm 1.31 ; \mathrm{MCT}=55.55 \pm 3.76 \%$; $\mathrm{P}<0.01$ ). CBX administration significantly decreased lung interstitial fibrosis $(\mathrm{MCT}=55.55 \pm 3.76$; $\mathrm{MCT}+\mathrm{CBX}=41.78 \pm 2.62 \%$; $\mathrm{P}<0.05$; Fig. $4 \mathrm{~A}$ and $\mathrm{B})$. The histological results suggest that CBX exerted protective effects on MCT-induced pulmonary vascular remodeling and lung fibrosis. 

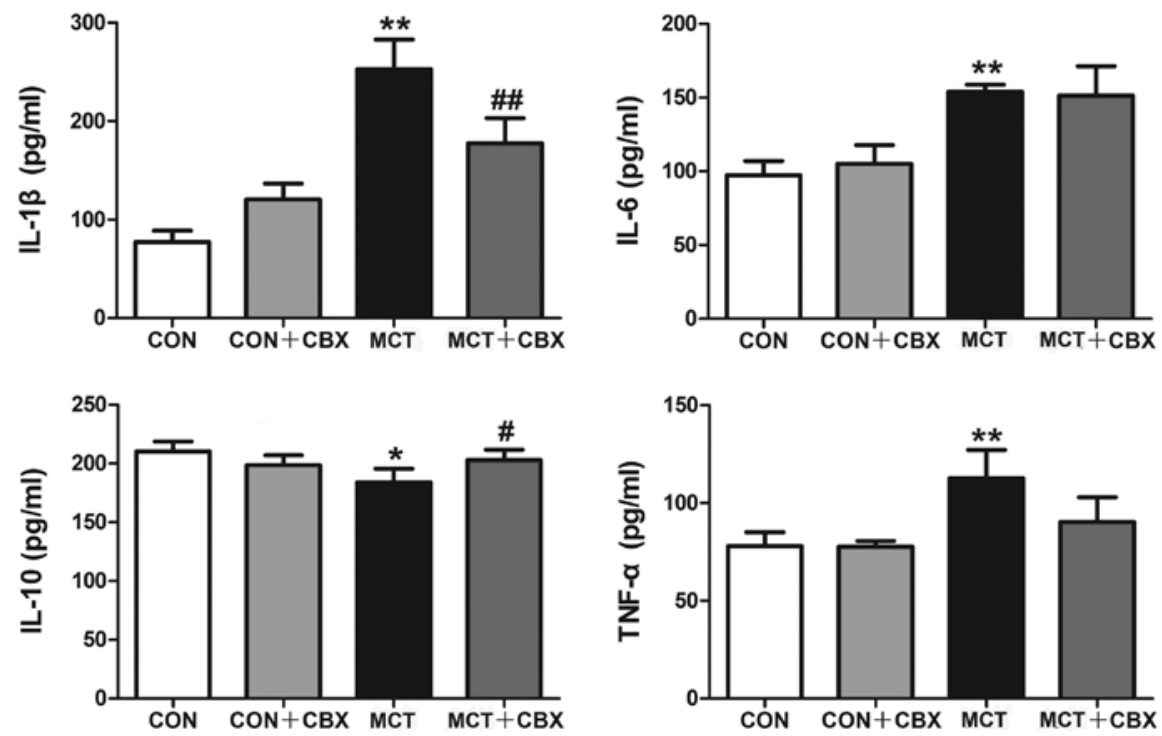

Figure 6. Effect of CBX on cytokine production in the serum of rats following treatment with MCT. Concentrations of IL-1 $\beta$, IL-6, IL-10 and TNF- $\alpha$ in the serum were measured by ELISA. Serum levels of IL-1 $\beta$, IL-6 and TNF- $\alpha$ were significantly increased in MCT-treated rats compared with the control rats. Serum levels of IL-10 were decreased in the MCT-treated rats compared with the control. The MCT-induced increase in the IL-1 $\beta$ level and decrease in the IL-10 level were significantly reversed in the CBX-treated rats. There were no significant differences in serum levels of IL- 6 and TNF- $\alpha$ between MCT-treated rats and the MCT $+\mathrm{CBX}$ group. Data are presented as the mean \pm standard error of the mean of 6 rats/group. ${ }^{*} \mathrm{P}<0.05$ and ${ }^{* *} \mathrm{P}<0.01$ vs. the control group. ${ }^{\#} \mathrm{P}<0.05$ and ${ }^{\# \#} \mathrm{P}<0.01$ vs. the MCT-treated group. CBX, carbenoxolone; IL, interleukin; MCT, monocrotaline; CON, control; TNF- $\alpha$, tumor necrosis factor- $\alpha$.

CBX administration prevents MCT-induced changes in cytokine production in lung tissues and serum. The inflammatory markers IL-1 $\beta$, IL- 6 , IL-10 and TNF- $\alpha$ serve pivotal roles in MCT-induced inflammation and pulmonary vascular remodeling (38). To identify the possible mechanisms involved in the beneficial effects of CBX on MCT-induced systemic inflammation in rats, the levels of these cytokines were measured in the lungs and serum using ELISAs. Compared with the control rats, lung tissues and serum from the MCT rats exhibited a significant increase in: IL-1 $\beta$ in the lung (Control=130.0 $\pm 6.23 \mathrm{pg} / \mathrm{ml} ; \mathrm{MCT}=702.50 \pm 27.86 \mathrm{pg} / \mathrm{ml}$; $\mathrm{P}<0.01$; Fig. 5) and serum (Control=77.16 $\pm 5.80 \mathrm{pg} / \mathrm{ml}$; $\mathrm{MCT}=253.0 \pm 15.13 \mathrm{pg} / \mathrm{ml} ; \mathrm{P}<0.01$; Fig. 6); IL-6 in the lung (Control=93.24 $\pm 2.87 \mathrm{pg} / \mathrm{ml} ; \mathrm{MCT}=232.3 \pm 15.05 \mathrm{pg} / \mathrm{ml}$; $\mathrm{P}<0.01$; Fig. 5) and serum (Control=97.20 $44.85 \mathrm{pg} / \mathrm{ml}$; $\mathrm{MCT}=153.90 \pm 2.44 \mathrm{pg} / \mathrm{ml} ; \mathrm{P}<0.01 ;$ Fig. 6); and TNF- $\alpha$ concentration in the lung (Control $=130.10 \pm 7.52 \mathrm{pg} / \mathrm{ml}$; $\mathrm{MCT}=243.10 \pm 11.39 \mathrm{pg} / \mathrm{ml} ; \mathrm{P}<0.01$; Fig. 5) and serum (Control=77.89 $\pm 3.58 \mathrm{pg} / \mathrm{ml} ; \mathrm{MCT}=112.70 \pm 7.28 \mathrm{pg} / \mathrm{ml} ; \mathrm{P}<0.01$; Fig. 6), and a significant decrease in IL-10 levels in the lung (Control=391.60 $\pm 21.09 \mathrm{pg} / \mathrm{ml} ; \mathrm{MCT}=227.80 \pm 15.30 \mathrm{pg} / \mathrm{ml}$; $\mathrm{P}<0.01$; Fig. 5) and serum (Control=210.20 $\pm 4.20 \mathrm{pg} / \mathrm{ml}$; $\mathrm{MCT}=184.20 \pm 5.69 \mathrm{pg} / \mathrm{ml} ; \mathrm{P}<0.05$; Fig. 6). In contrast, CBX administration significantly decreased the levels of pro-inflammatory cytokines: IL-1 $\beta$ (MCT $=702.50 \pm 27.86 \mathrm{pg} / \mathrm{ml} ; \mathrm{MCT}+\mathrm{CBX}=461.40 \pm 21.84$ $\mathrm{pg} / \mathrm{ml}), \mathrm{IL}-6(\mathrm{MCT}=232.30 \pm 15.05 \mathrm{pg} / \mathrm{ml} ; \mathrm{MCT}+\mathrm{CBX}$ $=145.80 \pm 4.00 \mathrm{pg} / \mathrm{ml})$ and TNF $-\alpha(\mathrm{MCT}=243.10 \pm 11.39$ $\mathrm{pg} / \mathrm{ml} ; \mathrm{MCT}+\mathrm{CBX}=149.50 \pm 7.18 \mathrm{pg} / \mathrm{ml}$ ) in lung tissues (all $\mathrm{P}<0.01$; Fig. 5) in MCT-treated rats, and significantly reduced the $\mathrm{MCT}$-induced increase in IL-1 $\beta$ (MCT $=253.00 \pm 15.13 \mathrm{pg} / \mathrm{ml} ; \mathrm{MCT}+\mathrm{CBX}=177.50 \pm 12.78 \mathrm{pg} / \mathrm{ml}$; $\mathrm{P}<0.01$; Fig. 6) in the serum; however, the MCT-induced increases in the serum levels of IL- 6 and TNF- $\alpha$ were not attenuated by CBX when compared with the MCT-treated group ( $\mathrm{P}>0.05$; Fig. 6). In addition, the levels of IL-10 in the lung $(\mathrm{MCT}=227.80 \pm 15.30 \mathrm{pg} / \mathrm{ml} ; \mathrm{MCT}+\mathrm{CBX}$ $=310.70 \pm 16.23 \mathrm{pg} / \mathrm{ml} ; \mathrm{P}<0.01 ;$ Fig. 5$)$ and serum $(\mathrm{MCT}$ $=184.20 \pm 5.69 \mathrm{pg} / \mathrm{ml} ; \mathrm{MCT}+\mathrm{CBX}=202.90 \pm 4.43 \mathrm{pg} / \mathrm{ml}$; $\mathrm{P}<0.05$, Fig. 6) of MCT-treated rats were significantly increased in the CBX treated rats. These results demonstrate that $\mathrm{CBX}$ administration may alleviate pulmonary inflammation induced by MCT in rats.

Administration of CBX alleviates MCT-induced lung inflammation. It has previously been reported that $\mathrm{T}$ lymphocytes serve a potential pathological role in MCT-induced pulmonary inflammation $(14,39)$ and in patients with PAH (39). To determine whether CBX prevented MCT-induced changes to the adaptive immune system, $T$ cell subset analysis in lung tissues was performed. As demonstrated in Fig. 7, in the rats treated with MCT, the percentages of the total $\mathrm{CD}^{+}($Control $=19.60 \pm 2.51 \%$; $\mathrm{MCT}=35.20 \pm 2.01 \%)$ and $\mathrm{CD}^{+}$(Control $=50.78 \pm 1.45 \%$; $\mathrm{MCT}=70.23 \pm 3.08 \%$ ) $\mathrm{T}$ cells in lung tissues were significantly increased (both $\mathrm{P}<0.01$; Fig. $7 \mathrm{~B}$ ), whereas $\mathrm{CD} 8^{+} \mathrm{T}$ cell counts were significantly decreased in the lungs of MCT-treated rats (Control=48.40 $\pm 2.39 \% ; \mathrm{MCT}=19.25 \pm 1.74 \% ; \mathrm{P}<0.01$; Fig. 7B) compared with the control rats. MCT treatment resulted in a significant disruption of the $\mathrm{CD} 4^{+} / \mathrm{CD} 8^{+} \mathrm{T}$ cell subset ratios (Control=1.28 \pm 0.17 ; MCT=3.26 $\pm 0.22 ; \mathrm{P}<0.01$; Fig. 7B) in the lung tissues. However, treatment with CBX resulted in significant decreases in the percentages of $\mathrm{CD}^{+}(\mathrm{MCT}=35.20 \pm 2.01 \% ; \mathrm{MCT}+\mathrm{CBX}=29.13 \pm 1.06 \%$; $\mathrm{P}<0.05), \mathrm{CD}^{+} \mathrm{T}$ cells $(\mathrm{MCT}=70.23 \pm 3.08 \%$; $\mathrm{MCT}+\mathrm{CBX}$ $=59.93 \pm 1.89 \% ; \mathrm{P}<0.05)$ and $\mathrm{CD}^{+} / \mathrm{CD}^{+} \mathrm{T}$ cell subset ratios $(\mathrm{MCT}=3.26 \pm 0.22 ; \mathrm{MCT}+\mathrm{CBX}=1.91 \pm 0.22 ; \mathrm{P}<0.01)$ as well as a significant increase in the percentage of $\mathrm{CD}^{+} \mathrm{T}$ cells $(\mathrm{MCT}=19.25 \pm 1.74 \% ; \mathrm{MCT}+\mathrm{CBX}=29.95 \pm 1.99 \% ; \mathrm{P}<0.01)$ compared with the MCT-treated rats (Fig. 7B). 
A
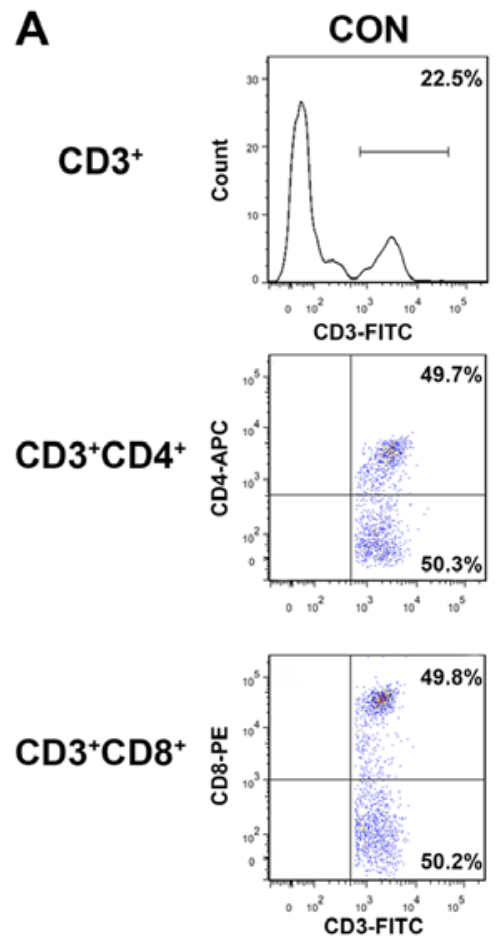

$\mathrm{CD}^{+} / \mathrm{CD}^{+}$

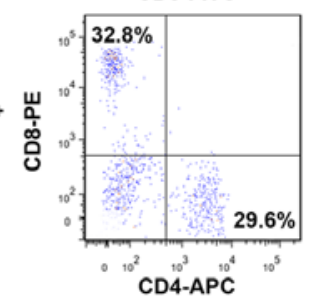

CON + CBX
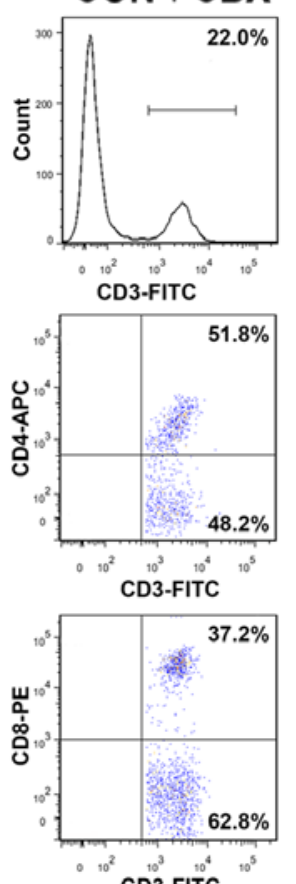

CD3-FITC

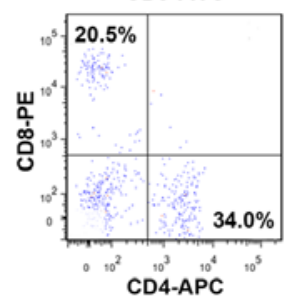

MCT
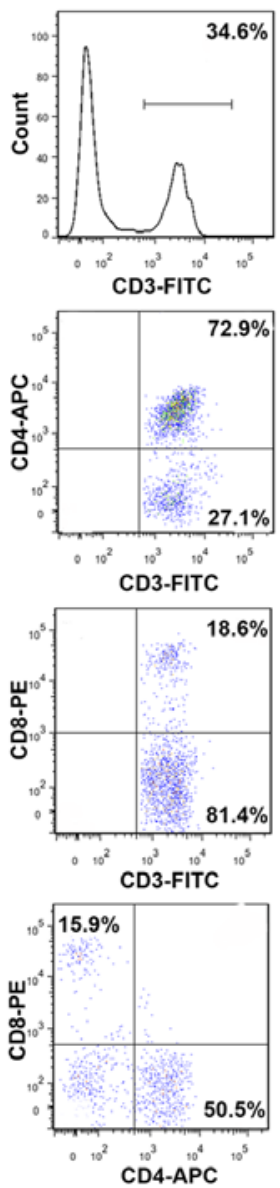

$\mathrm{MCT}+\mathrm{CBX} \mathrm{B}$
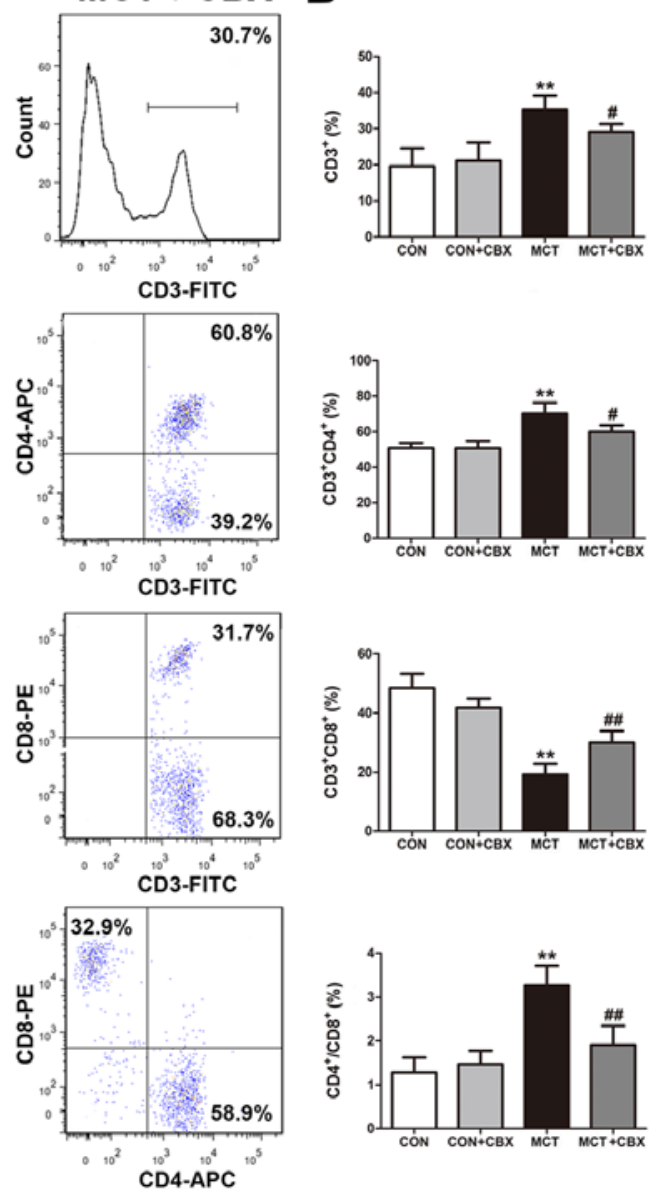

Figure 7. CBX administration reversed the changes in the proportions of $\mathrm{T}$ lymphocyte subtypes in the lungs of MCT-treated rats. (A) Gating for T lymphocytes among mononuclear cells and representative flow cytometry plots of pulmonary T lymphocytes subtypes $\left(\mathrm{CD}^{+}{ }^{+}\right.$and $\left.\mathrm{CD} 8^{+}\right)$. MCT-treated rats exhibited significantly increased levels of $\mathrm{CD}^{+}$and $\mathrm{CD}^{+} \mathrm{T}$ cell infiltration in the lungs. Intraperitoneal administration of $\mathrm{CBX}$ reversed the changes in the percentages of various T lymphocyte subpopulations in the lungs of the MCT-treated rats. (B) Bar graphs representing the proportions of various T cell subpopulations and $\mathrm{CD}^{+} / \mathrm{CD} 8^{+} \mathrm{T}$ cell subset ratios. Data are presented as the mean \pm standard error of the mean of 6 rats/group. ${ }^{* *} \mathrm{P}<0.01$ vs. control. ${ }^{~} \mathrm{P}<0.05$ and ${ }^{\# \# /} \mathrm{P}<0.01 \mathrm{vs}$. MCT-treated group. CBX, Carbenoxolone; CD, cluster of differentiation; CON, control; FITC, fluorescein isothiocyanate; PE, phycoerythrin; APC, allophycocyanin; MCT, monocrotaline; CON, control.

Treatment with CBX decreases Cx40 and Cx43 protein expression levels in T lymphocyte subsets in the lungs of $M C T$-treated rats. As the pro-inflammatory response is associated with upregulation of $\mathrm{Cx}$ expression or the functionality of Cx-mediated gap junction in T lymphocytes (16-18,40-42), the effect of MCT treatment on Cx expression in T lymphocytes in lung tissues of MCT-treated rats was studied, and in particular whether non-specific blocking of channels formed of Cx decreased MCT-induced pulmonary or systemic inflammation. Flow cytometry was used to detect $\mathrm{Cx} 40$ and $\mathrm{Cx} 43$ expression levels in $\mathrm{CD}^{+}$and $\mathrm{CD} 8^{+} \mathrm{T}$ lymphocyte subsets from lung tissues. As indicated in Fig. 8 and 9, the percentages of $\mathrm{CD}^{+} \mathrm{Cx}^{+} 0^{+}$(Control $=19.78 \pm 1.82 \%$; MCT $=34.85 \pm 2.97 \%$; $\mathrm{P}<0.01$; Fig. 8B), $\mathrm{CD}^{+} \mathrm{C}^{2} 40^{+}$(Control $=31.67 \pm 1.34 \%$; $\mathrm{MCT}=39.37 \pm 1.67 \% ; \mathrm{P}<0.05 ;$ Fig. $8 \mathrm{~B}), \mathrm{CD} 4{ }^{+} \mathrm{C} \times 43^{+}$ (Control=10.43 $\pm 1.76 \%$; $\mathrm{MCT}=32.07 \pm 2.91 \%$; $\mathrm{P}<0.01$; Fig. 9B) and $\mathrm{CD}^{+} \mathrm{Cx}_{43}{ }^{+}(\mathrm{Control}=24.17 \pm 2.15 \%$; $\mathrm{MCT}=34.90 \pm 1.90 \%$; $\mathrm{P}<0.05$; Fig. 9B) double-positive $\mathrm{T}$ lymphocytes were significantly increased in the lung tissues of MCT-treated rats compared with the control rats treated with normal saline. Compared with the MCT-treated group, CBX administration significantly decreased the MCT-induced increases in the percentages of $\mathrm{CD}^{+}{ }^{+} \mathrm{Cx} 40^{+}(\mathrm{MCT}, 34.85 \pm 2.97 \%$; $\mathrm{MCT}+\mathrm{CBX}$ $26.70 \pm 1.97 \%$; $\mathrm{P}<0.05$; Fig. $8 \mathrm{~B}), \mathrm{CD}^{+} \mathrm{Cx} 40^{+}$(MCT, $39.37 \pm 1.67 \%$; MCT + CBX 30.92 $\pm 2.30 \%$; $\mathrm{P}<0.05$; Fig. $8 \mathrm{~B})$,

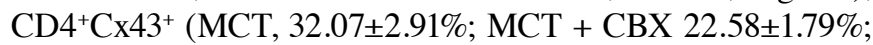
$\mathrm{P}<0.05$; Fig. 9B) and $\mathrm{CD} 8{ }^{+} \mathrm{Cx} 43^{+}$(MCT, $34.90 \pm 1.90 \%$; $\mathrm{MCT}+\mathrm{CBX}, 27.87 \pm 2.39 \%$; $\mathrm{P}<0.05$; Fig. 9B) double-positive $\mathrm{T}$ lymphocytes in lung tissues.

\section{Discussion}

Elevated PAP, pulmonary vascular remodeling and RVH are pathophysiological characteristics of $\mathrm{PH}$ (43) and MCT-induced lung damage (11). In the present study, PAP was assessed using the echo parameter, PAAT. A decrease in PAAT is associated with an increase in PAP (30). In the present study, MCT-induced lung damage was accompanied by a decrease in PAAT, an increase in RVHI and thickening of the pulmonary arteriole walls in the MCT-treated rats. A number of studies have demonstrated that inflammation is an important initial step of pulmonary arteriolar remodeling 
A

$\mathrm{CD} 4{ }^{+} \mathrm{Cx} 40^{+}$

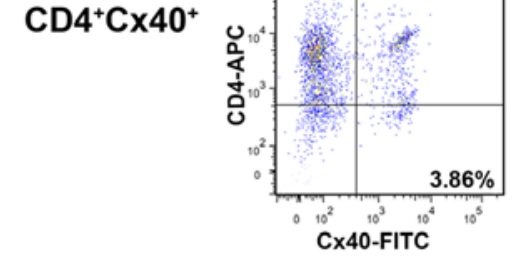

$\mathrm{CD} 8^{+} \mathrm{C} \times 40^{+}$

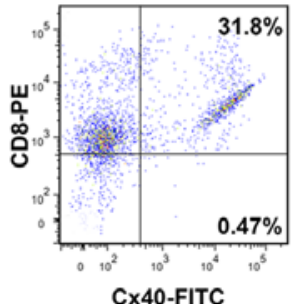

$\mathrm{CON}+\mathrm{CBX}$
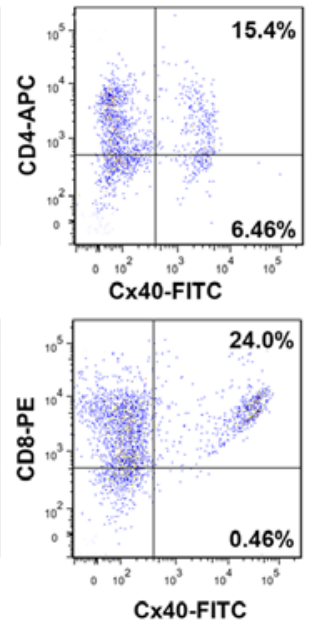

MCT
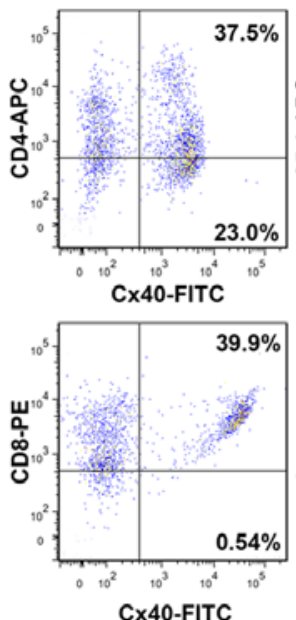

$\mathrm{MCT}+\mathrm{CBX}$
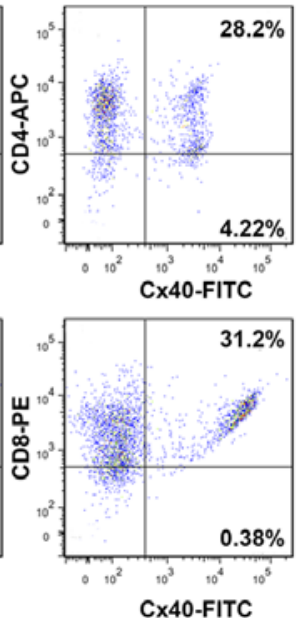

B
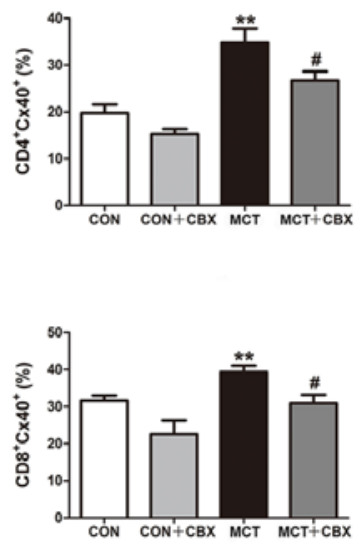

Figure 8. CBX administration decreases the percentages of $\mathrm{Cx} 40$-expressing $\mathrm{CD} 4^{+}$and $\mathrm{CD} 8^{+} \mathrm{T}$ cells in lung tissues of MCT-treated rats. (A) Representative dot plots of $\mathrm{CD}^{+} \mathrm{Cx} 40^{+}$or $\mathrm{CD} 8{ }^{+} \mathrm{Cx} 40^{+}$double-positive monocytes in lungs. (B) Quantitative analysis of the percentages of $\mathrm{CD} 4{ }^{+} \mathrm{Cx} 40^{+}$or $\mathrm{CD} 8^{+} \mathrm{Cx} 40^{+} \mathrm{T}$ cells indicated that the percentages of $\mathrm{CD} 4^{+} \mathrm{Cx} 40^{+}$and $\mathrm{CD} 8^{+} \mathrm{Cx} 40^{+} \mathrm{T}$ cells were significantly increased in the MCT-treated rats compared with the control group Compared with the MCT-treated group, the frequencies of $\mathrm{CD} 4{ }^{+} \mathrm{Cx} 40^{+}$and $\mathrm{CD} 8{ }^{+} \mathrm{Cx} 40^{+} \mathrm{T}$ cells were significantly decreased in the $\mathrm{MCT}+\mathrm{CBX}$ group. The frequencies of $\mathrm{CD} 4^{+} \mathrm{Cx} 40^{+}$and $\mathrm{CD} 8{ }^{+} \mathrm{Cx} 40^{+} \mathrm{T}$ cells were not significantly different between the lungs of control rats and the rats treated with a single intraperitoneal injection of CBX Data are presented as the mean \pm standard error of the mean of 6 rats/group. ${ }^{* *} \mathrm{P}<0.01$ vs. the control; ${ }^{*} \mathrm{P}<0.05$ vs. MCT-treated rats. APC, allophycocyanin; CBX, carbenoxolone; $\mathrm{CON}$, control; $\mathrm{Cx}$, connexin; $\mathrm{CD}$, cluster of differentiation; FITC, fluorescein isothiocyanate; MCT, monocrotaline.
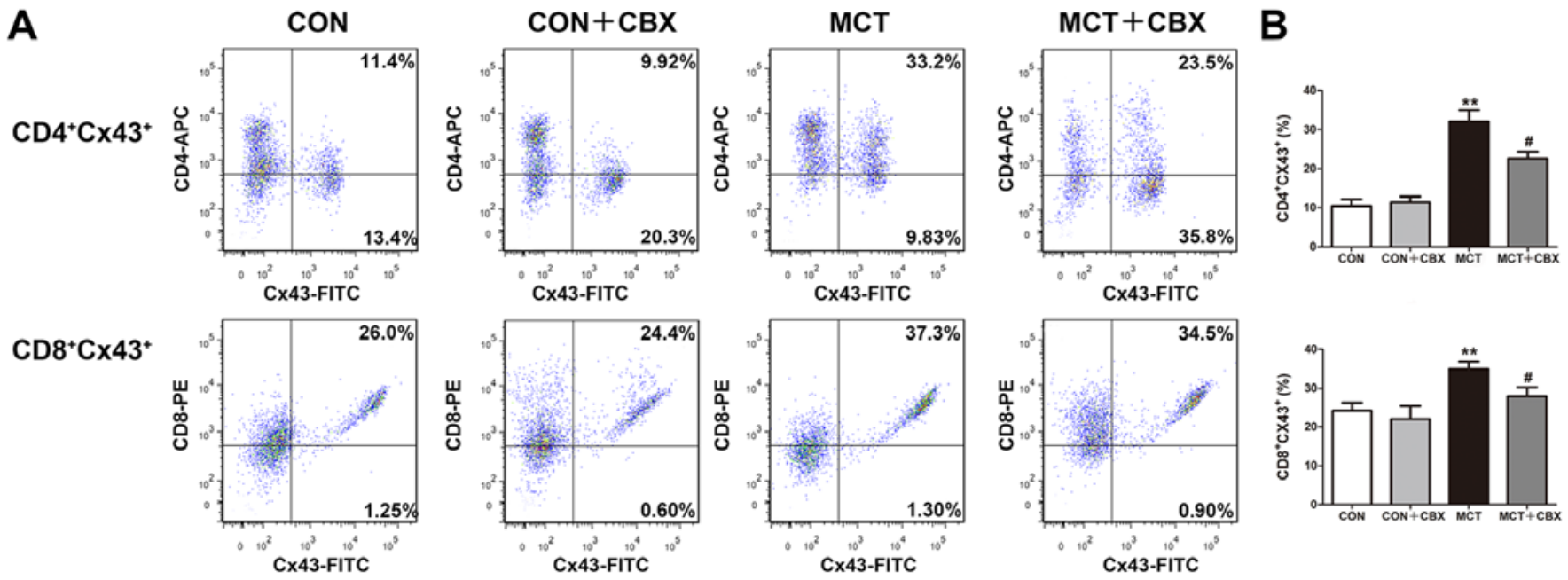

Figure 9. CBX administration decreases the percentages of $\mathrm{Cx} 43$-expressing $\mathrm{CD} 4^{+}$and $\mathrm{CD} 8^{+} \mathrm{T}$ cells in the lung tissues of the MCT-treated rats. (A) Representative flow cytometry plots and (B) quantitative analysis demonstrating the proportions of $\mathrm{CD} 44^{+} \mathrm{Cx} 43^{+}$or $\mathrm{CD} 8^{+} \mathrm{Cx} 43^{+}$double-positive $\mathrm{T}$ cells were increased in lung tissues of MCT-treated rats compared with the control group. There was a significant decrease in the frequencies of $\mathrm{CD} 4^{+} \mathrm{Cx} 43^{+}$and $\mathrm{CD} 8^{+} \mathrm{Cx} 43^{+} \mathrm{T}$ cells in the MCT + CBX-treated rats compared with the MCT-treated rats. The frequencies of $\mathrm{CD} 4^{+} \mathrm{Cx} 43^{+}$and $\mathrm{CD} 8^{+} \mathrm{Cx} 43^{+} \mathrm{T}$ cells did not significantly differ between the lungs of control rats and the rats treated with a single intraperitoneal injection of CBX. Data are presented as the mean \pm standard error of the mean of 6 rats/group. ${ }^{* *} \mathrm{P}<0.01$ vs. the control group. ${ }^{~} \mathrm{P}<0.05$ vs. the MCT-treated rats. APC, allophycocyanin; CBX, carbenoxolone; CON, control; Cx, connexin; CD, cluster of differentiation; FITC, fluorescein isothiocyanate; MCT, monocrotaline.

and lung damage in animal models of PH and patients with PH $(3,44)$, and these alterations are closely associated with the development and outcome of PH (44). The histopathological data corroborated these results, with notable inflammatory infiltration in the lungs of rats treated with MCT, accompanied by accumulation of the pro-inflammatory molecules, IL-1 $\beta$, IL- 6 and TNF- $\alpha$, in the lung tissues and serum. Inflammatory cells, in particular T lymphocytes, have been observed in the lungs and in the walls of resistance arteries in patients with PH (5). In the present study, the lung tissues exhibited significantly increased numbers of $\mathrm{CD} 4^{+} \mathrm{T}$ lymphocytes and significantly decreased numbers of $\mathrm{CD} 8^{+} \mathrm{T}$ lymphocytes in the MCT-treated rats. The elevation of $\mathrm{CD} 4^{+} \mathrm{T}$ cells and decrease in $\mathrm{CD}^{+} \mathrm{T}$ cells in the lungs of MCT rats was consistent with data from a previous study, which demonstrated the similar changes to the $\mathrm{T}$ lymphocyte counts in the peripheral blood of MCT-treated rats (2).

The presence of lung inflammation in pulmonary inflammatory diseases indicates that drugs targeting the adaptive immune component of the disease should be considered for treatment (13). The structures mediating direct cell-cell and cell extracellular environment interactions are Cxs, 
which form channels including gap junction channels and hemi-channels. Cxs participate in inflammatory responses and regulate production of cytokines $(40-42,45)$. Cx 40 and $\mathrm{Cx} 43$ in $\mathrm{T}$ cells may serve a pivotal role in mediating inflammatory changes $(40-42,46)$ and the progression of hypertension-mediated inflammatory response (16-20), as decreases in $\mathrm{Cx}$ expression or blocking of $\mathrm{Cx} 43$ channels in $\mathrm{T}$ cells resulted in a decreased production of inflammatory cytokines by $\mathrm{T}$ lymphocytes, decreased activation and proliferation of $\mathrm{T}$ lymphocytes and attenuated circulating inflammatory cell accumulation in spontaneously hypertensive rats and hypertensive patients (16-20). Therefore, Cxs represent novel potential targets for the treatment of cardiovascular disease induced chronic low-grade inflammation. To further ascertain the regulatory role of Cxs in T lymphocytes in MCT-induced PH mediated lung inflammation, and whether Cxs were a suitable target for therapeutic intervention in lung inflammation, $\mathrm{CBX}, \mathrm{a} \mathrm{Cx}$ inhibitor, was used to investigate the effect of inhibiting $\mathrm{Cx}$ function in lung inflammation and vascular remodeling in MCT-treated rats. Previous studies have demonstrated the effectiveness of CBX in the treatment of acute lung inflammation and pulmonary inflammatory diseases (22-24). CBX inhalation significantly alleviates asthma-induced lung inflammation by downregulating the production of inflammatory cytokines, and by decreasing inflammatory infiltration in perivascular areas (24). In addition, CBX has been suggested to be effective in the treatment of Th17-mediated autoimmune diseases by decreasing the number of Th17 cells and inhibiting the synthesis of IL-23 in antigen presenting cells (25). The present study demonstrated that CBX administration in the MCT-treated rats decreased PAAT, RVHI and pulmonary vascular remodeling. The data from the collagen staining assay also demonstrated a significant therapeutic effect of CBX in decreasing collagen fiber proliferation and inflammatory infiltration. Similarly, CBX administration decreased MCT-induced lung inflammation by downregulating the levels of IL-1 $\beta$, IL- 6 and TNF- $\alpha$, and by decreasing the counts of $\mathrm{CD}^{+} \mathrm{CD}^{+} \mathrm{T}$ cells in lung tissues. Furthermore, IL-10 levels, an anti-inflammatory cytokine, were increased in the lungs of CBX-administered rats. These results are similar to our previous studies $(17,19,20)$ indicating that gap junction blockers or anti-inflammatory agents $\left(\mathrm{H}_{2} \mathrm{~S}\right.$ donor and $\beta$-estradiol) prevent hypertension-mediated inflammation by decreasing inflammatory cytokine synthesis/secretion and preventing an imbalance between $\mathrm{T}$ cell subsets in experimental rats and patients with hypertension. The results suggest that CBX may alleviate MCT-induced PAH and may protect against MCT-induced inflammatory response by suppressing inflammation.

As aforementioned, our recent studies have demonstrated the role of $\mathrm{Cx}$-based gap junctions in hypertension-mediated inflammatory responses (16-20), and various anti-inflammatory agents and $\mathrm{Cx}$ blockers were observed to decrease inflammation by inhibiting $\mathrm{Cx}$ expression or function in peripheral blood lymphocytes of hypertensive animals and patients $(16,17)$. In an attempt to clarify the molecular mechanisms underlying the anti-inflammatory effects of CBX in MCT-mediated pulmonary inflammation in rats, the expression of $\mathrm{Cx} 40$ and Cx43 in T lymphocyte subsets was analyzed in lung tissue homogenates. The results indicated that the percentages of
$\mathrm{Cx} 40$ and $\mathrm{Cx} 43$ expressing $\mathrm{T}$ lymphocytes were upregulated in lungs of the MCT rats, indicating an association between Cxs in T lymphocytes and MCT-mediated lung inflammation. This suggests a functional significance of Cxs in controlling $\mathrm{T}$ lymphocyte-mediated pulmonary inflammation and pulmonary vascular remodeling. CBX administration decreased the percentages of $\mathrm{Cx} 40$ - and $\mathrm{Cx} 43$-expressing $\mathrm{T}$ lymphocytes in the lungs of MCT-treated rats. Therefore, it may be assumed that CBX exerts its anti-inflammatory and protective effects on lungs in MCT-treated by inhibiting $\mathrm{Cx} 40$ and $\mathrm{Cx} 43$ expression in T lymphocytes. These results highlight mononuclear Cxs as a potential target for treating pulmonary inflammation.

The present study has the following limitations. Firstly, only one animal model of MCT-induced pulmonary inflammation was established; other rodent models of PH or lung inflammation and larger animals should be examined, to verify long-term efficacy and safety of CBX therapy on PH or lung inflammation. Secondly, the present study did not analyze the expression levels of cytokines at the protein level by western blot analysis. Although the analysis of cytokines protein expression levels may provide a more convincing evidence for the therapeutic effect of CBX on MCT induced pulmonary inflammation, a recent study demonstrated that carbenoxolone may decrease pro-inflammatory cytokine levels in lungs [IL-17, C-C motif chemokine 5, chemokine (C-X-C motif) ligand 1, C-C motif chemokine 2, TNF- $\alpha$, and IL-6] in a murine model of lung ischemia-reperfusion injury (47). Therefore, carbenoxolone is hypothesized to prevent the production of pro-inflammatory cytokines from serum and lung in pulmonary inflammation. In addition, only 1 experimental method was used to detect the expression levels of Cxs. Future studies will be required to further determine the alterations of $\mathrm{Cxs}$ expression at a protein level in T lymphocytes of lung tissues and peripheral blood using immunoblotting. Thirdly, CBX has not exhibited a clear selectivity for any particular Cx subtypes; other mechanisms of action, unrelated to Cxs inhibition, are considered to be involved in their anti-inflammatory effects (43). Thus, only the specific blockade of $\mathrm{Cxs}$ in $\mathrm{T}$ lymphocytes completely explain the role of Cxs in MCT-induced pulmonary inflammation. Although we have also tried to prevent MCT-induced pulmonary inflammation in vivo by i.p. injection of $\mathrm{Cx} 43$ specific mimetic peptide Gap27 (Gap27), both chronic (4 weeks) and short-term (1 week) treatment schedules of Gap27 resulted in the death of normal and MCT-treated animals, owing to the systemic effect of Gap27 (Fan et al, unpublished data). Therefore, systemic knockdown of $\mathrm{Cx}$ or systemic inhibition of Cxs systemically may affect reproduction and life span or survival of experimental animals, which is not beneficial to the study of chronic lung inflammation. However, conditional $\mathrm{T}$ lymphocytes-specific knockdown of Cxs using Cre/loxP-regulated RNA interference (RNAi) may be the best choice for studying the role of Cxs in MCT or pulmonary hypertension mediated inflammation, although it is not clear whether RNAi knockdown of Cx43 will affect survival in hypertensive animals. Further studies will be designed to determine whether Cxs is involved in pulmonary inflammatory disease using conditional $\mathrm{T}$ lymphocyte-specific knockdown of Cxs, or small interfering RNA (siRNA) targeting of Cxs in $\mathrm{T}$ lymphocytes by siRNA strategies. Finally, although having determined the involvement of Cxs in pulmonary inflamma- 
tion in the present study and previous studies $(43,48)$, future studies are required to examine whether the changes of Cxs and the effect of CBX on Cxs are present in different pulmonary inflammation-associated cell types of the lung tissues, including pulmonary arterial endothelium, smooth muscle and alveolar macrophages.

Despite these limitations, the present study provided important evidence that Cxs and Cxs-based channels in $\mathrm{T}$ lymphocytes may have an important role in pulmonary inflammatory diseases, and inhibition of the Cxs-based channels using CBX attenuated MCT-induced pulmonary inflammation and pulmonary arteriolar thickening, as well as RVH by decreasing pulmonary inflammatory monocyte infiltration and inhibiting pro-inflammatory cytokine production in the lungs. The beneficial effects of CBX were accompanied by attenuation of $\mathrm{Cx} 40$ and $\mathrm{Cx} 43$ expression in T lymphocytes in lung tissues in the CBX-treated MCT rats. Together, the present and previous studies from our study group support the hypothesis that $\mathrm{Cx}$ and $\mathrm{Cx}$-based channels may be novel therapeutic targets for decreasing the $\mathrm{T}$ lymphocyte-mediated inflammatory response in $\mathrm{PH}$ and other pulmonary inflammatory diseases.

\section{Acknowledgements}

Not applicable.

\section{Funding}

The present study was supported by grants from the National Natural Science Foundation of China (grant no. 81660271 to KM; grant no. 81460098 to XL; grant no. 81600325 to LZ; and grant no. 81560081 to JS) and the International Cooperation Project of Shihezi University (grant no. GJHZ201603 to KM).

\section{Availability of data and materials}

The datasets used and/or analyzed during the present study are available from the corresponding author on reasonable request.

\section{Authors' contributions}

KM and JS conceived and designed the experiments. ZF, LW, LLi and XL performed the experiments. LZ, ZF and LLiu analyzed the data. LZ wrote the manuscript. All authors read and approved the final manuscript.

\section{Ethics approval and consent to participate}

The protocol of the study was approved by Institutional Animal Care and Use Committees (permit no. A2019-027-01) of the Medical College of Shihezi University, and all animal handling and experimental procedures were performed in accordance with guidelines for the Care and Use of Laboratory Animals published by the United States of America National Institutes of Health (26).

\section{Patient consent for publication}

Not applicable.

\section{Competing interests}

The authors declare that they have no competing interests.

\section{References}

1. Sada Y, Dohi Y, Uga S, Higashi A, Kinoshita H and Kihara Y: Non-suppressive regulatory T cell subset expansion in pulmonary arterial hypertension. Heart Vessels 31: 1319-1326, 2016.

2. Gao L, Liu J, Hao Y, Zhao Z, Tan H, Zhang J, Meng N, Zheng Q, Wang $\mathrm{Z}$ and Zhang Y: Chronic intermittent hypobaric hypoxia attenuates monocrotaline-induced pulmonary arterial hypertension via modulating inflammation and suppressing NF- $x \mathrm{~B} / \mathrm{p} 38$ pathway. Iran J Basic Med Sci 21: 244-252, 2018.

3. Deng Y, Guo SL, Wei B, Gao XC, Zhou YC and Li JQ: Activation of nicotinic acetylcholine $\alpha 7$ receptor attenuates progression of monocrotaline-induced pulmonary hypertension in rats by downregulating the NLRP3 inflammasome. Front Pharmacol 10: 128, 2019.

4. Chen F, Wang H, Zhao J, Yan J, Meng H, Zhan H, Chen L and Yuan L: Grape seed proanthocyanidin inhibits monocrotaline-induced pulmonary arterial hypertension via attenuating inflammation: In vivo and in vitro studies. J Nutr Biochem 67: 72-77, 2019

5. Austin ED, Rock MT, Mosse CA, Vnencak-Jones CL, Yoder SM, Robbins IM, Loyd JE and Meyrick BO: T lymphocyte subset abnormalities in the blood and lung in pulmonary arterial hypertension. Respir Med 104: 454-462, 2010.

6. Savai R, Pullamsetti SS, Kolbe J, Bieniek E, Voswinckel R, Fink L, Scheed A, Ritter C, Dahal BK, Vater A, et al: Immune and inflammatory cell involvement in the pathology of idiopathic pulmonary arterial hypertension. Am J Respir Crit Care Med 186: 897-908, 2012.

7. Rabinovitch $M$, Guignabert $C$, Humbert $M$ and Nicolls MR: Inflammation and immunity in the pathogenesis of pulmonary arterial hypertension. Circ Res 115: 165-175, 2014.

8. Yang JM,Zhou R,Zhang M,Tan HR and Yu JQ: Betaine attenuates monocrotaline-induced pulmonary arterial hypertension in rats via inhibiting inflammatory response. Molecules 23: E1274, 2018.

9. Pang Y, Liang MT, Gong Y, Yang Y, Bu PL, Zhang M and Yao HC: HGF reduces disease severity and inflammation by attenuating the NF- $x \mathrm{~B}$ signaling in a rat model of pulmonary artery hypertension. Inflammation 41: 924-931, 2018.

10. Li XQ, Wang HM, Yang CG, Zhang XH, Han DD and Wang HL: Fluoxetine inhibited extracellular matrix of pulmonary artery and inflammation of lungs in monocrotaline-treated rats. Acta Pharmacol Sin 32: 217-222, 2011.

11. Nogueira-Ferreira R, Vitorino R, Ferreira R and HenriquesCoelho T: Exploring the monocrotaline animal model for the study of pulmonary arterial hypertension: A network approach. Pulm Pharmacol Ther 35: 8-16, 2015.

12. Zhang B, Niu W, Xu D, Li Y, Liu M, Wang Y, Luo Y, Zhao P, Liu Y, Dong M, et al: Oxymatrine prevents hypoxia- and monocrotaline-induced pulmonary hypertension in rats. Free Radic Biol Med 69: 198-207, 2014.

13. Cohen-Kaminsky S, Hautefort A, Price L, Humbert $M$ and Perros F: Inflammation in pulmonary hypertension: What we know and what we could logically and safely target first. Drug Discov Today 19: 1251-1256, 2014.

14. Wang W, Wang YL, Chen XY, Li YT, Hao W, Jin YP and Han B: Dexamethasone attenuates development of monocrotaline-induced pulmonary arterial hypertension. Mol Biol Rep 38: 3277-3284, 2011.

15. Zhao H, Xue Y, Guo Y, Sun Y, Liu D and Wang X: Inhibition of endocan attenuates monocrotaline-induced connective tissue disease related pulmonary arterial hypertension. Int Immunopharmacol 42: 115-121, 2017.

16. Ni X, Li XZ, Fan ZR, Wang A, Zhang HC, Zhang L, Li L, Si JQ and Ma KT: Increased expression and functionality of the gap junction in peripheral blood lymphocytes is associated with hypertension-mediated inflammation in spontaneously hypertensive rats. Cell Mol Biol Lett 23: 40, 2018.

17. Ni X, Wang A, Zhang L, Shan LY, Zhang HC, Li L, Si JQ, Luo J, Li XZ and Ma KT: Up-regulation of gap junction in peripheral blood $\mathrm{T}$ lymphocytes contributes to the inflammatory response in essential hypertension. PLoS One 12: e0184773, 2017. 
18. Zhang HC, Zhang ZS, Zhang L, Wang A, Zhu H, Li L, Si JQ, $\mathrm{Li} X Z$ and Ma KT: Connexin 43 in splenic lymphocytes is involved in the regulation of $\mathrm{CD} 4{ }^{+} \mathrm{CD} 25^{+} \mathrm{T}$ lymphocyte proliferation and cytokine production in hypertensive inflammation. Int J Mol Med 41: 13-24, 2018.

19. Ni X, Zhang L, Ma X, Shan LY, Li L, Si JQ, Li XZ, Zhang YY and Ma KT: $\beta$-estradiol alleviates hypertension- and concanavalin A-mediated inflammatory responses via modulation of connexins in peripheral blood lymphocytes. Mol Med Rep 19: 3743-3755, 2019.

20. Ni X, Zhang L, Peng M, Shen TW, Yu XS, Shan LY, Li L, Si JQ, Li XZ and Ma KT: Hydrogen sulfide attenuates hypertensive inflammation via regulating connexin expression in spontaneously hypertensive rats. Med Sci Monit 24: 1205-1218, 2018.

21. Manjarrez-Marmolejo J and Franco-Pérez J: Gap Junction Blockers: An overview of their effects on induced seizures in animal models. Curr Neuropharmacol 14: 759-771, 2016.

22. O'Donnell JJ III, Birukova AA, Beyer EC and Birukov KG: Gap junction protein connexin43 exacerbates lung vascular permeability. PLoS One 9: e100931, 2014.

23. Suzuki S, Matsuda Y, Sugawara T, Tabata T, Ishibashi H, Hoshikawa Y, Kubo $\mathrm{H}$ and Kondo T: Effects of carbenoxolone on alveolar fluid clearance and lung inflammation in the rat. Crit Care Med 32: 1910-1915, 2004.

24. Ram A, Singh SK, Singh VP, Kumar S and Ghosh B: Inhaled carbenoxolone prevents allergic airway inflammation and airway hyperreactivity in a mouse model of asthma. Int Arch Allergy Immunol 149: 38-46, 2009.

25. Endong L, Shijie J, Sonobe Y, Di M, Hua L, Kawanokuchi J, Mizuno T and Suzumura A: The gap-junction inhibitor carbenoxolone suppresses the differentiation of Th17 cells through inhibition of IL-23 expression in antigen presenting cells. J Neuroimmunol 240-241: 58-64, 2011.

26. Bayne K: Revised Guide for the Care and Use of Laboratory Animals Available. American Physiological Society. Physiologist 39: 199, 208-211, 1996.

27. Sharma S, Sharma N, Saini A and Nehru B: Carbenoxolone reverses the amyloid Beta 1-42 oligomer-induced oxidative damage and anxiety-related behavior in rats. Neurotox Res 35: 654-667, 2019.

28. Urboniene D, Haber I, Fang YH, Thenappan T and Archer SL: Validation of high-resolution echocardiography and magnetic resonance imaging vs. high-fidelity catheterization in experimental pulmonary hypertension. Am J Physiol Lung Cell Mol Physiol 299: L401-L412, 2010.

29. Temple IP, Monfredi O, Quigley G, Schneider H, Zi M, Cartwright EJ, Boyett MR, Mahadevan VS and Hart G: Macitentan treatment retards the progression of established pulmonary arterial hypertension in an animal model. Int J Cardiol 177: 423-428, 2014.

30. Flues K, Moraes-Silva IC,Mostarda C, Souza PR, Diniz GP, Moreira ED, Piratello AC, Chaves ML, De Angelis K, Salemi VM, et al: Cardiac and pulmonary arterial remodeling after sinoaortic denervation in normotensive rats. Auton Neurosci 166: 47-53, 2012.

31. Lang RM, Bierig M, Devereux RB, Flachskampf FA, Foster E, Pellikka PA,Picard MH, Roman MJ, Seward J, Shanewise JS, et al; Chamber Quantification Writing Group; American Society of Echocardiography's Guidelines and Standards Committee; European Association of Echocardiography: Recommendations for chamber quantification: A report from the American Society of Echocardiography's Guidelines and Standards Committee and the Chamber Quantification Writing Group, developed in conjunction with the European Association of Echocardiography, a branch of the European Society of Cardiology. J Am Soc Echocardiogr 18: 1440-1463, 2005.

32. Ji WJ, Ma YQ, Zhou X, Zhang YD, Lu RY, Guo ZZ, Sun HY, $\mathrm{Hu}$ DC, Yang GH, Li YM, et al: Spironolactone attenuates bleomycin-induced pulmonary injury partially via modulating mononuclear phagocyte phenotype switching in circulating and alveolar compartments. PLoS One 8: e81090, 2013.

33. Lei L,HeZY,Zhao C, Sun XJ and Zhong XN: Elevated frequencies of CD4(+) IL-21(+) T, CD4(+) IL-21R(+) T and IL-21(+) Th17 cells, and increased levels of IL-21 in bleomycin-induced mice may be associated with dermal and pulmonary inflammation and fibrosis. Int J Rheum Dis 19: 392-404, 2016.
34. Barletta KE, Cagnina RE, Wallace KL, Ramos SI, Mehrad B and Linden J: Leukocyte compartments in the mouse lung: Distinguishing between marginated, interstitial, and alveolar cells in response to injury. J Immunol Methods 375: 100-110, 2012.

35. Martinu T, Kinnier CV, Sun J, Kelly FL, Nelson ME, Garantziotis S, Foster WM and Palmer SM: Allogeneic splenocyte transfer and lipopolysaccharide inhalations induce differential T cell expansion and lung injury: A novel model of pulmonary graft-versus-host disease. PLoS One 9: e97951, 2014.

36. Alencar AKN, Pimentel-Coelho PM, Montes GC, da Silva MMC, Mendes LVP, Montagnoli TL, Silva AMS, Vasques JF, Rosado-de-Castro PH, Gutfilen B, et al: Human mesenchymal stem cell therapy reverses Su5416/hypoxia-induced pulmonary arterial hypertension in mice. Front Pharmacol 9: 1395, 2018.

37. Li L, Wei C, Kim IK, Janssen-Heininger Y and Gupta S: Inhibition of nuclear factor- $x \mathrm{~B}$ in the lungs prevents monocrotaline-induced pulmonary hypertension in mice. Hypertension 63: 1260-1269, 2014.

38. Yamazato Y, Yamazato M, Ishida A, Fujita J and Ohya Y: Intratracheal administration of autologous bone marrow-derived cells ameliorates monocrotaline-induced pulmonary vessel remodeling and lung inflammation in rats. Lung 196: 147-155, 2018.

39. Marsh LM, Jandl K, Grünig G, Foris V, Bashir M, Ghanim B, Klepetko W, Olschewski H, Olschewski A and Kwapiszewska G: The inflammatory cell landscape in the lungs of patients with idiopathic pulmonary arterial hypertension. Eur Respir J 51: 1701214, 2018.

40. Sáez PJ, Shoji KF, Aguirre A and Sáez JC: Regulation of hemichannels and gap junction channels by cytokines in antigen-presenting cells. Mediators Inflamm 2014: 742734, 2014.

41. Oviedo-Orta E, Hoy T and Evans WH: Intercellular communication in the immune system: Differential expression of connexin40 and 43 , and perturbation of gap junction channel functions in peripheral blood and tonsil human lymphocyte subpopulations. Immunology 99: 578-590, 2000

42. Mendoza-Naranjo A, Bouma G, Pereda C, Ramírez M, Webb KF, Tittarelli A, López MN, Kalergis AM, Thrasher AJ, Becker DL, et al: Functional gap junctions accumulate at the immunological synapse and contribute to $\mathrm{T}$ cell activation. J Immunol 187: 3121-3132, 2011.

43. Freund-Michel V, Muller B, Marthan R, Savineau JP and Guibert C: Expression and role of connexin-based gap junctions in pulmonary inflammatory diseases. Pharmacol Ther 164: 105-119, 2016.

44. Feng S, Chen S, Yu W, Zhang D, Zhang C, Tang C, Du J and Jin H: $\mathrm{H} 2 \mathrm{~S}$ inhibits pulmonary arterial endothelial cell inflammation in rats with monocrotaline-induced pulmonary hypertension. Lab Invest 97: 268-278, 2017.

45. Willebrords J, Crespo Yanguas S, Maes M, Decrock E, Wang N, Leybaert L, Kwak BR, Green CR, Cogliati B and Vinken M: Connexins and their channels in inflammation. Crit Rev Biochem Mol Biol 51: 413-439, 2016.

46. Meloche J,Renard S, Provencher S and Bonnet S: Anti-inflammatory and immunosuppressive agents in PAH. Handb Exp Pharmacol 218: 437-476, 2013.

47. Sharma AK, Charles EJ, Zhao Y, Narahari AK, Baderdinni PK, Good ME, Lorenz UM, Kron IL, Bayliss DA, Ravichandran KS, et al: Pannexin-1 channels on endothelial cells mediate vascular inflammation during lung ischemia-reperfusion injury. Am J Physiol Lung Cell Mol Physiol 315: L301-L312, 2018.

48. Billaud M, Dahan D, Marthan R, Savineau JP and Guibert C: Role of the gap junctions in the contractile response to agonists in pulmonary artery from two rat models of pulmonary hypertension. Respir Res 12: 30, 2011.

This work is licensed under a Creative Commons Attribution-NonCommercial-NoDerivatives 4.0 International (CC BY-NC-ND 4.0) License. 